\title{
Postnatal Development of the Spatial Contrast Sensitivity of $X-$ and Y-Cells in the Kitten Retinogeniculate Pathway
}

\author{
John S. Tootle and Michael J. Friedlander \\ Neurobiology Research Center and Department of Physiology and Biophysics, University of Alabama at Birmingham, \\ Birmingham, Alabama 35294
}

\begin{abstract}
The sensitivity to spatial contrast patterns of single retinal ganglion cell axons and neurons in the A-layers of the dorsal lateral geniculate nucleus $\left(\mathrm{LGN}_{\mathrm{d}}\right)$ was measured in $41 / 2$ - and 61/2-week-old kittens and adult cats. Drifting sinusoidal grating stimuli were presented at 6-12 spatial frequencies to obtain spatial contrast sensitivity functions (SCSFs). The SCSFs were normalized for the postnatal growth of the kitten eye and were interpreted using a difference of Gaussians model of the receptive field (RF). The average optimal spatial frequency, spatial frequency bandwidth, and the proportion of cells that were selective for spatial frequency did not differ significantly between the kittens and adults for ganglion cells belonging to the cluster $1(\mathrm{X}-)$ or cluster 2 (Y-) functional types. The spatial resolution of kitten ganglion cells was also adultlike, except for that of Y-ganglion cells with peripheral RFs, which was significantly higher than in the adult. The spatial resolution of X-LGN ${ }_{d}$ neurons with peripheral RFs was significantly poorer at $4 \frac{1}{2}$ weeks than in the older animals. The proportion of $X-L_{G N}$ neurons that were selective for spatial frequency increased between $41 / 2$ and $61 / 2$ weeks postnatally, but the spatial frequency bandwidth of selective cells did not change. The increased proportion of spatially selective $L_{G N}$ neurons is probably due to the maturation of intrageniculate inhibitory circuits. Developmental changes in spatial resolution were interpreted as resulting from an increase (Y-retinal ganglion cells) or decrease $\left(X-L G N_{d}\right.$ neurons) in RF center size. A model of retinogeniculate development is presented that attributes postnatal expansion of Y-retinal ganglion cell RF centers to increased functional convergence from more distal retinal neurons and reduction in $L G N_{d} X$-cell RF center size to decreased convergence from $X$-retinal ganglion cells.
\end{abstract}

\footnotetext{
Received Mar. 23, 1988; revised Aug. 5, 1988; accepted Aug. 23, 1988.

This research was supported by Grant BNS- 8720069 from the National Science Foundation and by the Alfred P. Sloan Foundation. We are grateful to Patty Summerlin and Judy Rodda for technical support, and to Diana Pullen for excellence in word processing. Kevin Ramer and Jill Gemmill developed computer software for data acquisition, analysis, and color graphics. We also thank Read Montague for the curve-fitting program for the difference of Gaussians model and Dr. Kathy Kirk of the Department of Biostatistics and Biomathematics at the University of Alabama at Birmingham for many helpful discussions concerning cluster analysis and other multivariate techniques. Glaxovet Inc. generously provided the Saffan anesthetic.

Correspondence should be addressed to Dr. M. J. Friedlander, Neurobiology Research Center, University of Alabama at Birmingham, Birmingham, AL 35294. Copyright (C) 1989 Society for Neuroscience $0270-6474 / 89 / 041325-16 \$ 02.00 / 0$
}

The spatial contrast sensitivity of retinal ganglion cells (EnrothCugell and Robson, 1966; Derrington and Lennie, 1982; EnrothCugell et al., 1983) and neurons of the dorsal lateral geniculate nuclcus $\left(\mathrm{LGN}_{\mathrm{d}}\right)($ Derrington and Fuchs, 1979; Lchmkuhlc ct al., 1980; Troy, 1983a, b) is well documented in adult cats. Neurons of the retinogeniculate pathway act as spatial frequency filters by responding to a limited range of frequencies. The highest frequency to which a cell responds is termed its acuity or spatial resolution. In addition, many retinogeniculate neurons show a reduced sensitivity to spatial frequencies below an optimum that yields maximum sensitivity, while others are maximally sensitive to contrast modulation of a spatially uniform field (zero spatial frequency). As a result these neurons are described, respectively, to behave as bandpass and low-pass spatial frequency filters. The spatial contrast sensitivity of many adult retinogeniculate neurons can be adequately explained by a model in which the receptive field (RF) is made up of a center and surround mechanism, each with a Gaussian spatial sensitivity profile (Rodieck, 1965; Enroth-Cugell and Robson, 1966; So and Shapley, 1981; Linsenmeier et al., 1982). Along with neurons of the visual cortex that have similar spatial frequency filtering properties (Movshon et al., 1978; Tolhurst and Thompson, 1981), retinogeniculate neurons are believed to constitute a neural correlate of the spatial frequency channels demonstrated psychophysically in cats (Blake and Martens, 1981; Berkley, 1984) and other species (see Braddick et al., 1978; DeValois and DeValois, 1980; and Westheimer, 1984, for reviews).

Despite the many studies in the adult cat, we are aware of no studies of the spatial contrast sensitivity of kitten retinal ganglion cells during postnatal development. Moreover, in the 3 studies that reported contrast sensitivity measurements for $\mathrm{LGN}_{\mathrm{d}}$ neurons during postnatal development (Ikeda and Tremain, 1978; Wilson et al., 1982; Mangel et al., 1983), spatial contrast sensitivity functions (SCSFs) have been presented for a total of only $5 \mathrm{LGN}_{\mathrm{d}}$ neurons at ages less than 8 weeks postnatally, the period when much of the developmental change in the structure (Friedlander, 1982, 1984; Mason, 1983; Sur et al., 1984; Friedlander et al., 1985) and synaptology (Winfield and Powell, 1980; Winfield et al., 1980; Mason, 1982) of the $\mathrm{LGN}_{d}$ occurs. This lack of detailed information on the development of the spatial processing characteristics of the primary drive to the visual cortex is surprising in light of the considerable attention paid to the devclopment of such propertics of cortical ncurons (sec Movshon and Van Sluyters, 1981; Sherman and Spear, 1982; Fregnac and Imbert, 1984; Friedlander and Tootle, 1989, for reviews). For example, Derrington and Fuchs (1981) and Derrington (1984) measured SCSFs for neurons in the striate cortex 
and found that their peak sensitivity, spatial resolution, and optimal spatial frequency increase significantly during the first 6-10 postnatal weeks. Spatial frequency selectivity improved both in terms of the number of selective cells and the narrowness of spatial frequency tuning curves up to about 6 postnatal weeks. Moreover, the results of Braastad and Heggelund (1985) and Albus and Wolf (1984) from their studies of visual cortical neurons in young kittens suggest that the retinogeniculate afferents may be immature with regard to their spatial processing properties.

The purpose of the present study was to directly evaluate the postnatal development of the spatial processing capacities of functionally identified retinogeniculate $\mathrm{X}$ - and $\mathrm{Y}$-cells in normally reared kittens. In order to study the development of spatial contrast sensitivity separately for the functional types of cells established in adult animals (X-and $\mathrm{Y}-$ ), the neuronal types of the immature neonatal neurons were identified by means of multivariate cluster analysis (Tootle and Friedlander, 1987b). The SCSFs were analyzed within the context of the differencc of Gaussians model of the receptive field and were expressed in terms of distance on the retina after scaling for the postnatal growth of the kitten eye (Thorn et al., 1976; G. S. Tucker, personal communication). The differences in the spatial integration by $\mathrm{X}$ - and $\mathrm{Y}$-neurons within the retina and $\mathrm{LGN}_{\mathrm{d}}$ were compared at each age in order to evaluate the relative contribution of intraretinal and intrageniculate circuitry to the spatial filtering of signals routed to the primary visual cortex during development. Some preliminary results of the present study have been reported previously (Tootle and Friedlander, 1985, 1987a).

\section{Materials and Methods}

Subjects. Forty-two kittens and 12 adult cats served as subjects in the experiments and represent a subset of the subjects used in a study of the development of neuronal types in the retinogeniculate system (Tootle and Friedlander, 1987b). Kitten ages ranged from 26 to $36 \mathrm{~d}\left(4 \frac{1}{2}-\right.$ week-old group, $n=24)$ or from 42 to $48 \mathrm{~d}\left(6 \frac{1}{2}\right.$-week-old group, $n=$ 18). The weights of the adult cats were all greater than $2 \mathrm{~kg}$.

Surgical preparation. General anesthesia was induced with $2-4 \%$ halothane (Abbott) in a 1:1 mixture of $\mathrm{O}_{2}$ and $\mathrm{N}_{2} \mathrm{O}$. The femoral artery and vein were cannulated, the halothane was discontinued, and anesthesia was then maintained by infusing intravenously a mixture of alphaxalone and alphadalone acetate (Saffan-Glaxovet, $2.0 \mathrm{mg} / \mathrm{ml}$ ) as needed. The trachea and femoral artery were cannulated to allow, respectively, artificial ventilation and monitoring of blood pressure during subsequent paralysis and electrophysiological recording. Wound margins and pressure points were infiltrated with procaine and butamben in oil (Anduracaine-Reid Provident), and the animal was placed in a stereotaxic instrument. Paralysis was induced by a $10-30 \mathrm{mg}$ dose of gallamine triethiodide (Flaxedil, Davis \& Geck) and was maintained by an intravenous infusion of Flaxedil $(12 \mathrm{mg} / \mathrm{kg} / \mathrm{hr}$ for kittens, $35 \mathrm{mg} / \mathrm{kg} / \mathrm{hr}$ for adults) in 5\% lactated Ringer's solution. Adult cats also received 0.9 $\mathrm{mg} / \mathrm{kg} / \mathrm{hr}$ of tubocurarine chloride (Squib).

A craniotomy was performed over each $\mathrm{LGN}_{\mathrm{d}}$ and a Plexiglas chamber was cemented to the skull surrounding the craniotomy. The dura was cut and retracted to allow introduction of glass micropipettes into the brain during subsequent electrophysiological recordings. To assure stability during recordings, both chambers were filled with a $3 \%$ agar solution in saline and sealed with paraffin.

A pair of stimulating electrodes made of tungsten, insulated to within about $1 \mathrm{~mm}$ of the tip, was positioncd across the optic chiasm (OX) and cemented into place at the position where a maximal amplitude visually evoked response was recorded. Expired $\mathrm{CO}_{2}$ was monitored with a Beckman LB-II CO $\mathrm{CO}_{2}$ monitor and was kept between 3.8 and $4.2 \%$. Body temperature was fixed at $38^{\circ} \mathrm{C}$ with a feedback heating blanket circuit. Throughout the recording procedures the animals routinely received $0.5-3.0 \mathrm{mg} / \mathrm{kg} / \mathrm{hr}$ Saffan (i.v.). Adequacy of anesthesia was assessed continuously by monitoring blood pressure and heart rate. When needed, supplemental anesthesia was produced with additional doses of Saffan.

Electrophysiological recording. Action potentials of retinal ganglion cell axons and $\mathrm{LGN}_{\mathrm{d}}$ neurons were recorded extracellularly with glass micropipettes filled with a solution of $0.2 \mathrm{M} \mathrm{KCl}, 0.05 \mathrm{M}$ tris(hydroxymethyl)aminomethane (Tris, Sigma) and 4\% HRP (Sigma VI) at $\mathrm{pH}$ of 7.0 or with a $3 \mathrm{M} \mathrm{NaCl}$ solution. Micropipette tips were beveled to an impedance of 90-150 M (HRP-filled) or 25-60 M $\Omega$ $\left(\mathrm{NaCl}-\right.$ filled) at $200 \mathrm{~Hz}$. Action potentials of $\mathrm{LGN}_{\mathrm{d}}$ neurons were recognized by their biphasic waveform, the variability in their response latency to electrical stimulation of the OX (especially at high frequencies) and the reliability of their response to visual stimulation when compared with the responses of neurons in the perigeniculate nucleus, which were often recorded prior to encountering the $\mathrm{LGN}_{d}$ in a microelectrode penetration. In some experiments several cells were impaled with the micropipette and iontophoretically filled with HRP. In every such case, histological processing of the tissue confirmed the placement of the electrode in the $\mathbf{L G N}_{\mathrm{d}}$ A-layers. Action potentials of retinal ganglion cell axons were recognized by their vigorous responses to visual stimulation, short latencies to electrical stimulation of the $\mathrm{OX}$, monophasic waveform, and lack of jitter in their response latency to electrical stimuli presented at $125 \mathrm{~Hz}$. The activity of retinal ganglion cells was recorded in the optic tract just ventral and lateral to the LGN

For quantitative study, action potentials were converted to standard pulses, which were sent to the Schmitt trigger input on a clock module of a PDP 11/23 computer. Raw data, which consisted of the elapsed time between the beginning of a cycle of contrast modulation and the occurrence of an action potential, were stored on a hard disk for subsequent off-line analysis.

Visual stimulation and classification tests. The pupils of both eyes were dilated with atropine sulfate (Alcon) and the nictitating membranes were retracted with $10 \%$ phenylephrine $\mathrm{HCl}$ (Neosynephrine, Winthrop) or with $1 \%$ hydroxyamphetamine hydrobromide (Paredrine, Smith Kline \& French). The corneas were protected with opaque, plano contact lenses containing a $3 \mathrm{~mm}$ artificial pupil. Refraction necessary to focus visual stimuli on the retina was determined by streak retinoscopy and was supplied by spectacle lenses placed in front of the eyes.

RFs of retinal ganglion cells and $\mathrm{LGN}_{d}$ neurons were plotted with flashing spot stimuli that were projected (pantoscope-Keeler) onto a tangent screen at a viewing distance of $114 \mathrm{~cm}$. The spots had diameters of $0.5^{\circ}-2.5^{\circ}$, a luminance of $3.0 \mathrm{~cd} / \mathrm{m}^{2}(1.5 \mathrm{log}$ units above background) and were used to determine several features of the RF organization: RF center size, contrast sign (on or off) and position. Quantitative testing was conducted with stimuli that were produced on the display of a Tektronix model 608 monitor using a Picasso image generator (Innisfree). The monitor was positioned tangential to the cornea at a distance of $20-57 \mathrm{~cm}$ and raster size was $10 \times 10 \mathrm{~cm}$. For cell classification tests the stimuli consisted of vertically oriented sinusoidal gratings whose contrast (luminance $_{\max }-$ luminance $_{\min } /$ /uminance $_{\max }+$ luminance $_{\min }$ ) was modulated in counterphase about a mean luminance of $44 \mathrm{~cd} / \mathrm{m}^{2}$ or which were drifted to the animal's right at a fixed contrast of 0.6 .

Assignment of neurons to functional classes. Retinal ganglion cells and $\mathrm{LGN}_{\mathrm{d}}$ neurons were placed into functional groups (clusters) using the CLUSTER procedure of the SAS statistical package (SAS Inst. Inc., 1985) and a set of classification measures including the following.

1. Linearity of spatial summation. The "null test" (Enroth-Cugell and Robson, 1966) was used to assess spatial summation. The contrast of a sinusoidal grating stimulus that covered an area including the entire $\mathrm{RF}$ of each neuron was modulated in counterphase. The spatial phase of the grating was adjusted to yield no (or minimal) response and the cells response to 50 cycles of contrast modulation was recorded with the computer. The spatial phase was shifted, and the process was repeated until 2-15 phase positions were tested. The data were reconstructed as peristimulus time histograms with a bin width of $10 \mathrm{msec}$, and their temporal harmonic content was determined by Fourier analysis. A linearity index was calculated as the ratio of the greatest amplitude of the second-harmonic response to the greatest amplitude of the fundamental response, where response amplitude was $1 /$ number of bins times the square root of the sum of squares of the sine and cosine coefficients at the appropriate frequency. Since the frequency-doubling nonlinearity is sometimes weak and labile in young animals (Mangel et al., 1983; Sur et al., 1984; Tootle and Friedlander, 1986), the "null test" was often conducted at several spatial frequencies, including one near the resolution limit of each cell (Hochstein and Shapley, 1976a, b).

2. Temporal resolution. Temporal resolution was defined as the high- 

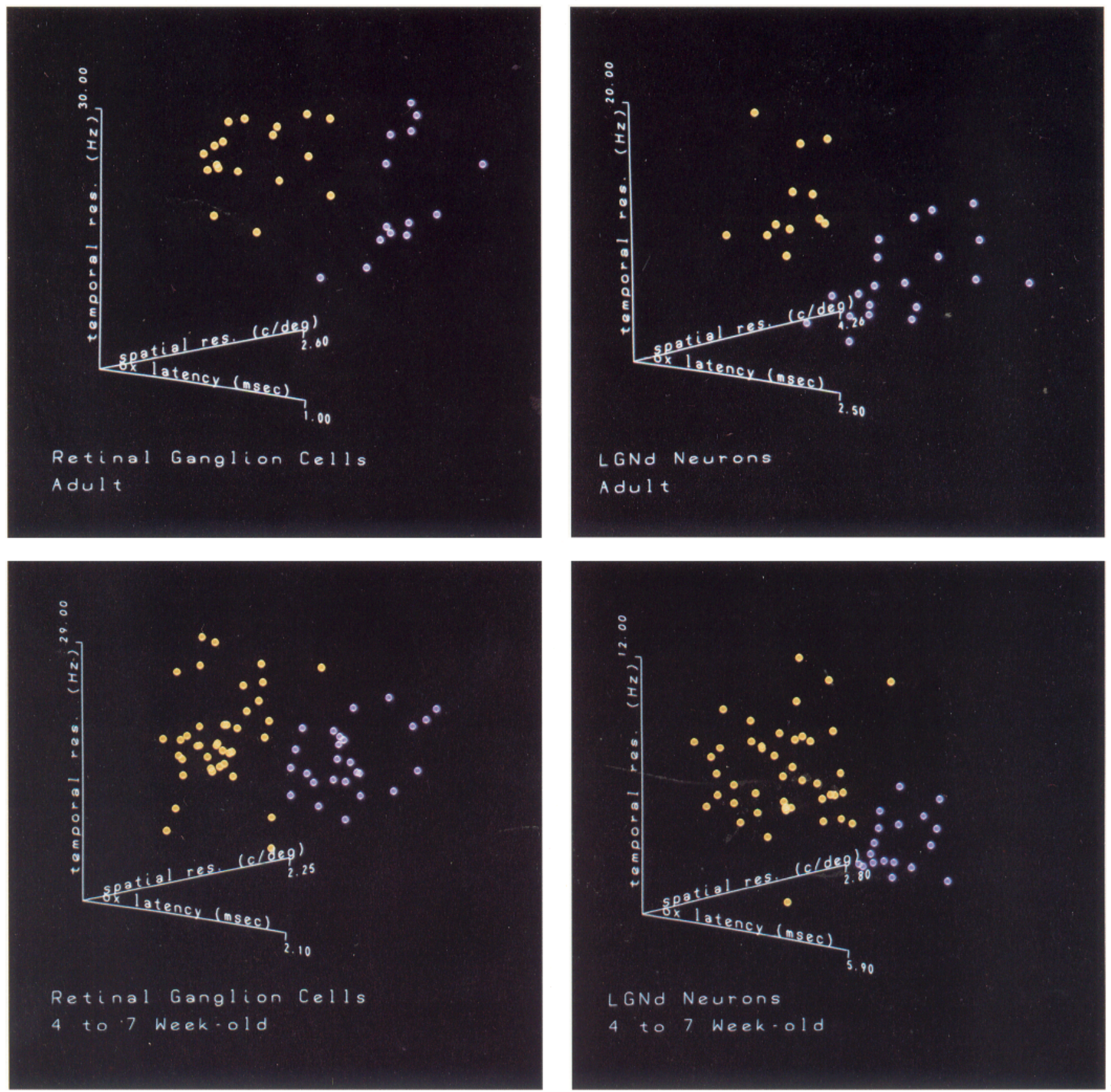

Figure 1. Distribution of neurons belonging to clusters 1 (blue symbols) and 2 (yellow symbols) in multivariate measurement space. The clusters were formed with the CLUSTER procedure of the SAS statistical package (SAS Inst. Inc., 1985). Coordinate data consisting of the scores for each neuron on tests of spatial resolution, temporal resolution, linearity of spatial summation, and latency (or probability) of response to optic chiasm $(O X)$ stimulation were standardized to a mean of zero and unit SD and were clustered using Ward's minimum variance method. The appropriate

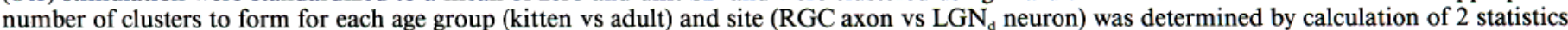
$\left(R^{2}\right.$ and pseudo $\left.F\right)$, which reflect the proportion of the total variance accounted for by the clusters. Cross-tabulation of cluster membership with $\mathrm{X}-, \mathrm{Y}$-, and W-cell types (identified by means of previously published criteria) reveals near identity of cells belonging to clusters 1 and 2 , respectively, with X-and Y-cells in adult animals. The same relationship was established for the kitten neurons, despite the immature responses of the kitten neurons on some physiological tests.

est temporal frequency at which a neuron gave a modulated response to each cycle of a grating stimulus (of optimal spatial frequency) drifting across its RF. For kitten $\mathrm{LGN}_{\mathrm{d}}$ neurons which had little or no spontaneous activity and poor temporal responses, the resolution was noted by listening to the response on the audio monitor while adjusting the drift frequency. The resolution frequency was easily discernible since increasing the drift frequency beyond the resolution limit produced "missing beats" in the rhythmical discharge of the cell to the passage of each bar of the grating across the RF. For adult $\mathrm{LGN}_{\mathrm{d}}$ neurons and for retinal ganglion cells at all ages studied, the responses of each cell to 50 cycles of a drifting grating stimulus were collected with the computer for several temporal frequencies estimated to span the temporal resolution frequency. The resolution frequency was then determined visually from raster plots of the cell's response to the drifting grating 


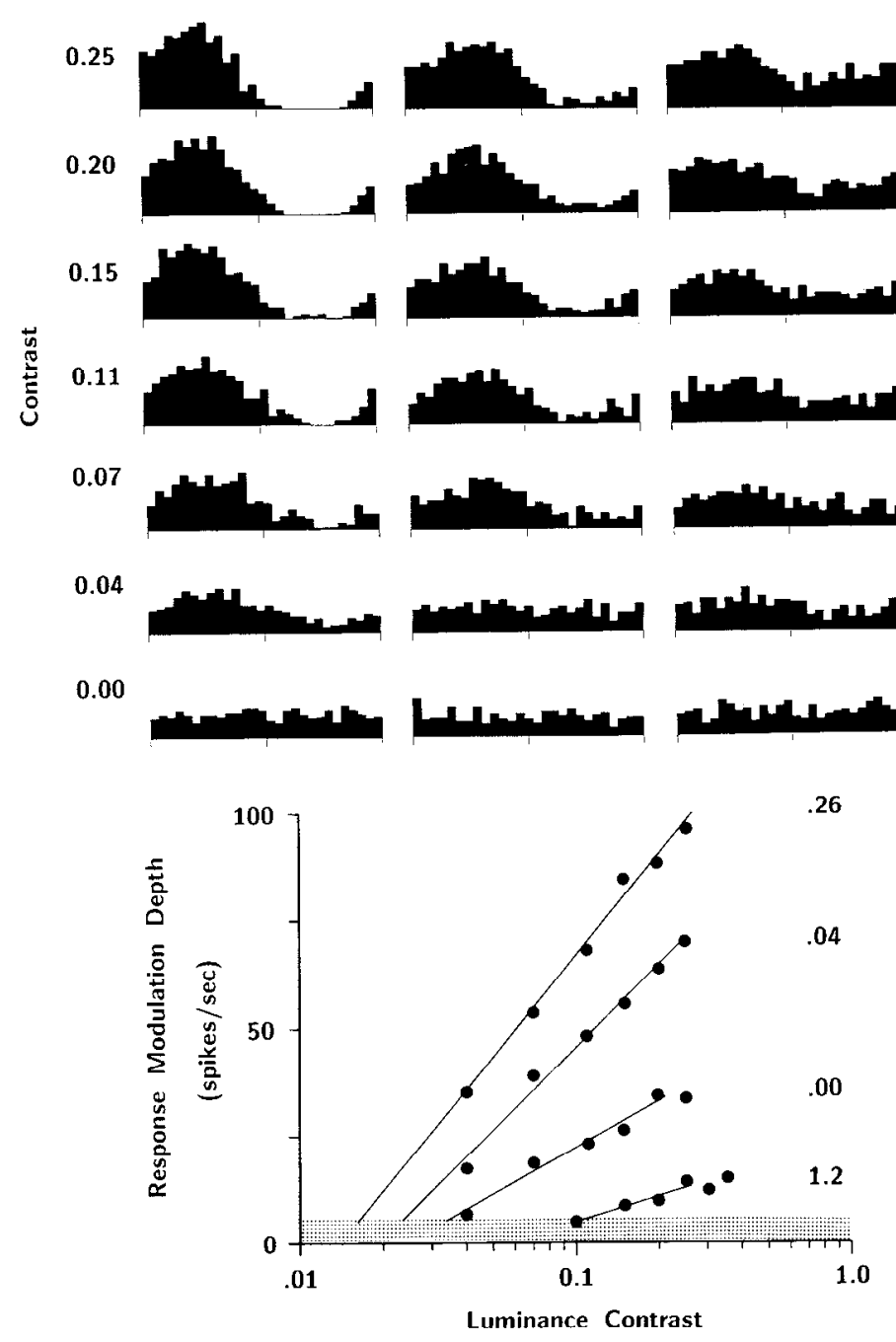

0.35

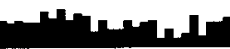

0.30

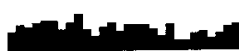

0.25

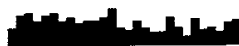

0.20

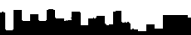

0.15

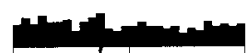

0.10

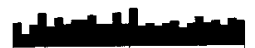

0.00

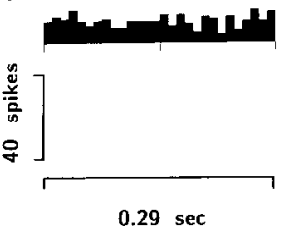
contrast. The regression lines are the best least-squares fit for the regression of response amplitude on the logarithm of stimulus contrast. Contrast thresholds for each spatial frequency were taken to be the contrast corresponding to the response amplitude at the intersection of the regression line and baseline activity (stippled region at bottom of graph). The latter was measured as the mean plus $2 \mathrm{SD}$ of the response to zero contrast gratings presented at each spatial frequency tested. The contrast sensitivity is the inverse of the contrast threshold.

on a cycle-by-cycle basis and was the highest frequency where a modulated response could been seen on each of the 50 cycles.

3 . Spatial resolution. Spatial resolution was defined as the highest spatial frequency at which a modulated response of criterion amplitude ( 2 SD above baseline activity) could be evoked from each cell. It was calculated from an objectively determined spatial contrast sensitivity function as described below.

4. Latency of response to electrical stimulation of the $O X$. The latency of each neuron's response to electrical stimulation of the OX was measured as the elapsed time between the stimulus artifact and the foot of the evoked action potential for 10-20 constant current stimuli (duration, $100 \mu \mathrm{sec}$; amplitude, $0.5-5.0 \mathrm{~mA}$ ). The latency was taken to be the modal latency for neurons showing a clear mode and was otherwise measured as the midpoint of the scatter of latencies where no mode was obvious.

5. Probability of response to OX stimulation. Many of the $\mathrm{LGN}_{\mathrm{d}}$ ncurons in the kittens were difficult to activate by electrical stimulation of the $\mathrm{OX}$. For these cells, probability of response to OX stimulation was used as a classification variable. It was defined as the proportion of 50 electrical stimuli delivered to the OX that evoked an action potential from each neuron. Stimuli were constant-current pulses with an amplitude of $5.0 \mathrm{~mA}$ and duration of $100 \mu \mathrm{sec}$.

Multivariate cluster analysis of the samples of retinogeniculate neurons based upon the classification variables revealed that 2 clusters were formed for retinal ganglion cells and $\mathrm{LGN}_{\mathrm{d}}$ neurons at each age studied. The distributions of the neurons belonging to the 2 clusters are shown in Figure 1, in which the axes represent 3 of the variables used for classification. For both the kittens and adult cats, the retinal ganglion cells and $\mathrm{LGN}_{\mathrm{d}}$ neurons in cluster $1 \mathrm{had}$, on average, longer latencies (or lower probabilities) of response to OX stimulation, poorer temporal resolution, higher spatial resolution, and more linear spatial summation than did those in cluster 2 . In the adult animals, the neurons in clusters 1 and 2 correspond, closely and respectively, to $\mathrm{X}$ - and $\mathrm{Y}$-cells as identified by a standard battery of electrophysiological tests applied in the context of conventional classification schemes (Stone, 1983). In the kittens, clusters 1 and 2 also contain, respectively, cells belonging to the $\mathrm{X}$ - and $\mathrm{Y}$-types based on the relative position of the cells in each cluster in the multivariate space. The 2 cell types were recognizable in the kittens despite their immature responses on some classification tests. For example, many kitten $\mathrm{LGN}_{d}$ cluster $2(\mathrm{Y}-)$ cells had not yet developed the nonlinear frequency-doubling response typical of members of this class in adult cats. The details of the cluster analysis are presented in a separate communication (Tootle and Friedlander, submitted for publication).

Spatial contrast sensitivity measurements. The spatial contrast sensitivity of each neuron was measured using drifting sinusoidal gratings, with the drift rate adjusted to be near the temporal frequency optimal for evoking a response from the cell. The average drift frequency used was approximately $2.5 \mathrm{~Hz}(\mathrm{SD}<0.8)$, except for $\mathrm{LGN}_{\mathrm{d}}$ neurons at $41 / 2$ weeks postnatally, at which time poor temporal responsiveness prompted the use of an average drift rate of $1.6 \mathrm{~Hz}$. At these temporal frequencies little phase shift should occur between the outputs of the center and surround mechanisms (Derrington and Lennie, 1982; Enroth-Cugell et al., 1983; Troy, 1983b), which should remain approximately $180^{\circ}$ 
out of phase. Typically, gratings of 7 different spatial frequencies and contrasts (including a zero contrast condition for each spatial frequency) were presented in a randomized, interleaved order. The order of presentation of the 49 spatial frequency by contrast conditions was randomized and the responses to 5 cycles of contrast modulation were collected for each condition. The randomization process was repeated after each block of 5 cycles of contrast modulation and recordings were made until the summed responses to 15-30 cycles had been collected. The responses to each combination of conditions were reconstructed as stimulus time histograms, examples of which can be seen in Figure 2 for a retinal ganglion cell from a 42-d-old kitten. The stimulus time histograms were subjected to Fourier analysis and the amplitude of the response at the drift frequency of the grating was calculated. For each spatial frequency tested, a linear regression of response amplitude on the logarithm of stimulus contrast was performed over the range of contrasts where the relationship was linear (Fig. 2, bottom). The contrast sensitivity for a given spatial frequency was calculated from the regression line as the inverse of the contrast required to produce a criterion response, whose amplitude was equal to the mean plus $2 \mathrm{SD}$ of the response to the zero contrast gratings. This is illustrated in the graph in Figure 2, where the top edge of the stippled region indicates the criterion amplitude response. The criterion response amplitude was about 4-6 spikes/sec for the retinal ganglion cells at all ages studied. The low spontaneous activity of the kitten $\mathrm{LGN}_{\mathrm{d}}$ neurons yielded average criterion response amplitudes of $0.6-0.8$ spikes/sec versus an average of 2.3 spikes/sec for $L G N_{d}$ neurons in the adult. Thus changes in firing rates of less than 1 spike/sec could bring kitten $L_{G N}$ neurons to statistical threshold.

From determinations of contrast sensitivity at 6-12 spatial frequencies, a SCSF like the one shown in the upper graph of Figure 3 was constructed for each neuron. The smooth curve drawn through the data points is the best least-squares fit to the data of the following equation:

$$
s(\nu)=k_{c} \pi r_{c}^{2} \exp \left[\left(-\pi r_{c} \nu\right)^{2}\right]-k_{s} \pi r_{s}^{2} \exp \left[\left(-\pi r_{s} \nu\right)^{2}\right],
$$

where $s$ is the contrast sensitivity at spatial frequency $\nu, k_{c}$ and $k_{s}$ are the peak sensitivities of the RF center and surround mechanisms, and $r_{c}$ and $r_{s}$ are the characteristic radii at which the sensitivity of center and surround have declined to $1 / e$ of the peak value. Fits of equation (1) to the contrast sensitivity data for each neuron were determined by a computer program using the method of steepest descent. The program found the values of the 4 fitting parametcrs $\left(r_{c}, k_{c}, r_{s}, k_{s}\right)$ of equation (1) which minimized the sum of the squared errors between it and the contrast sensitivity data. The goodness of the fit was calculated as the average squared error per data point, i.e., as the sum of the squared errors divided by the number of data points. Equation (1) assumes that the RF of the neuron is made up of concentric, circular center and surround mechanisms with Gaussian spatial sensitivity profiles and that the output of the cell is proportional to the difference in the output of the mechanisms, i.e., the center and surround signals add in opposite phase.

The curves obtained by fitting equation (1) were used to calculate the values of several features of the spatial contrast sensitivity function for each neuron studied. These are illustrated in upper Figure 3 and were as follows.

1. Spatial resolution. The highest spatial frequency to which a neuron responded, i.e., where sensitivity declined to a value of 1 .

2. Optimal spatial frequency (OSF). For cells with a decline in sensitivity at low spatial frequencies, the OSF was the spatial frequency yielding maximum contrast sensitivity.

3. Bandwidth (BW). Spatial frequency BW was quantified in octaves as the logarithm (base 2) of the ratio of the spatial frequency above optimal where sensitivity had declined by $1 / 2(0.3 \log$ units $)$ the peak sensitivity to the spatial frequency below optimal yielding the same decline in sensitivity. Cells that had no low-frequency sensitivity reduction or that had a reduction less than $0.3 \mathrm{log}$ units in magnitude were designated as low pass.

4. Contrast sensitivity ratio. The contrast sensitivity ratio was an index of the magnitude of the decline in sensitivity at low spatial frequencies. It was quantified as the ratio of the sensitivity at a spatial frequency $0.63 \log$ units below OSF $(0.2 \times \mathrm{OSF})$ to the peak sensitivity. For cells with no decrease in sensitivity at low spatial frequencies, the contrast sensitivity ratio was assigned a value of 1 .

The spatial contrast sensitivity measurements were also used to study developmental changes in the RFs of retinogeniculate neurons (Fig. 3,
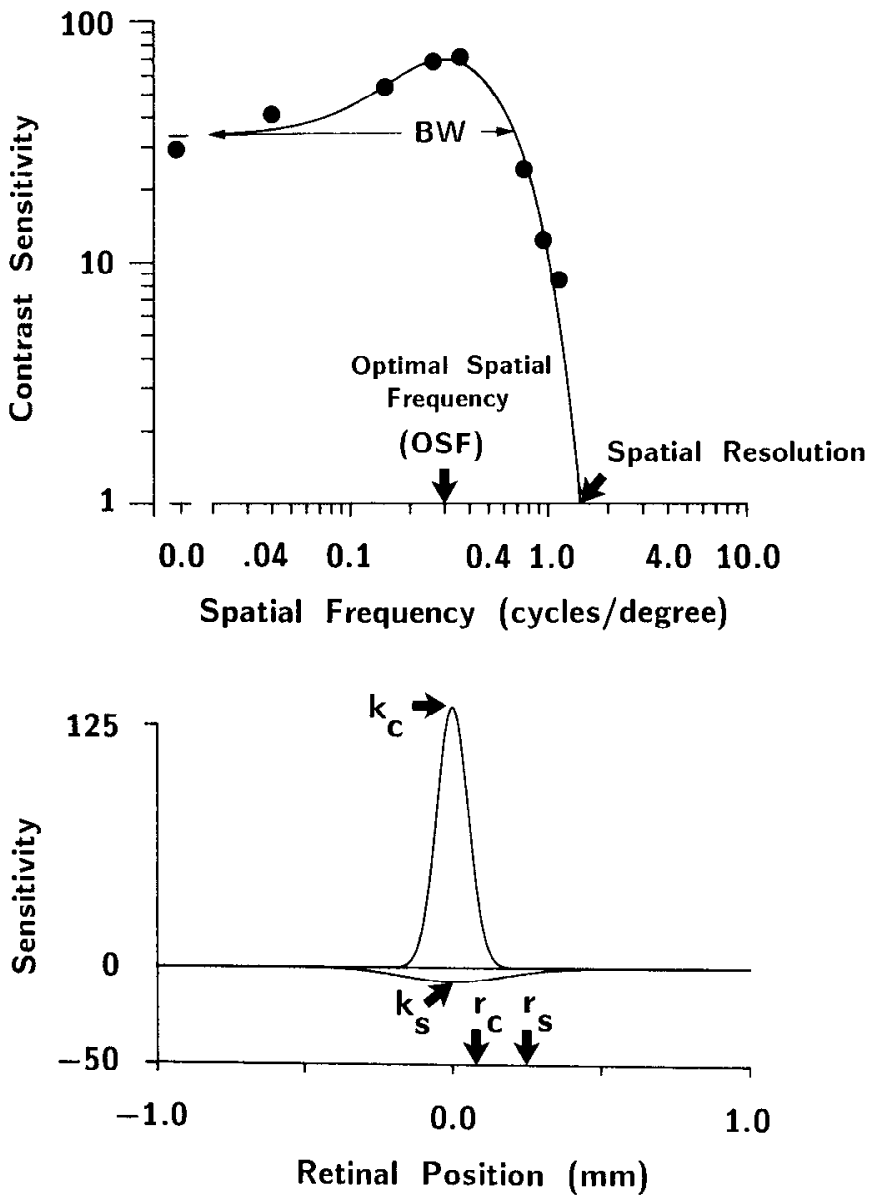

Figure 3. Illustration of several features of the SCSFs that were analyzed quantitatively (upper graph) and the spatial sensitivity profile derived from the contrast sensitivity function assuming a difference of Gaussians model of the RF (lower graph). The smooth curve is the best least-squares fit of equation (1) to the sensitivity data from the retinal ganglion cell whose responses are shown in Figure 2. The features of the SCSFs examined included spatial resolution, OSF, and spatial frequency BW. Lower graph shows the spatial sensitivity profile derived from the best least-squares fit of the SCSF in the upper plot. The RF center and surround each have a Gaussian sensitivity profile that is completely specified by a peak sensitivity $\left(k_{c}\right.$ and $k_{s}$ for the center and surround, respectively) and a characteristic radius ( $r_{c}$ and $r_{s}$, respectively) at which the sensitivity has fallen to a value of $1 / e$ of the peak sensitivity. Notice that the radius has been converted from degrees of visual angle to millimeters of retinal extent. This was accomplished by using an estimate of the posterior nodal distance of the eye to calculate the distance on the retina subtending $1^{\circ}$ of visual angle (in the present case, $0.161 \mathrm{~mm}$ ) and scaling accordingly. The result provides an estimate of the neural extent of the RF, which may reveal changing patterns of functional convergence or dendritic extent during development.

lower). RF center and surround sizes and sensitivities were taken directly as the values of the 4 fitting parameters of equation (1).

Optics. In order to interpret neurophysiological data like those obtained in the present study, 2 developmental features of the optics of the kitten eye must be considered. The first is that a degradation in the quality of the retinal image is produced by a transient vascular membrane that engulfs the lens until about 4-5 weeks postnatally (Thorn et al., 1976; Bonds and Freeman, 1978; Freeman and Lai, 1978). Prior to these ages the immature optics can alter the spatial distribution of light in the retinal image of stimuli, e.g., spots, bars, traditionally used to obtain RF measurements (Shapley and Lennie, 1985) but do not alter the spatial frequency of sinusoidal grating stimuli like those used in the present study. The second feature is that the growth of the kitten eye between $4 \frac{11}{2}$ weeks postnatally and adulthood produces a significant increase in the magnification of the retinal image (Vakkur et al., 1963; 


\section{RETINAL GANGLION CELLS}

Figure 4. Example of spatial contrast sensitivity data with lines of best fit for retinal ganglion cells from $4 \frac{1 / 2-}{\text { - }}$ and $61 / 2$ week-old kittens and adult cats. The data are presented separately for cells belonging to clusters 1 and 2 . The data shown are representative for each age and cluster. The upper 2 functions in each group have been displaced upwards $1 \log$ unit each along the sensitivity axis for clarity of presentation. Median errors (sum of the squared deviations of each data point from the predicted sensitivity divided by the number of data points) for the $41 / 2,61 / 2$, and adult age groups, respectively, were $5.1,12.7$, and 2.6 for cluster 1 (X-) ganglion cells and $6.3,3.4$, and 6.5 for cluster 2 (Y-) ganglion cells. The fits obtained for cluster 1 cells at $6^{1 / 2}$ weeks postnatally were poorer than those obtained for the adult $(p<0.01)$, but no other age comparisons were significant. In the adult, fitting errors obtained for cluster 2 cells tended to be greater than for cluster 1 cells but not significantly so $(p>0.05)$.

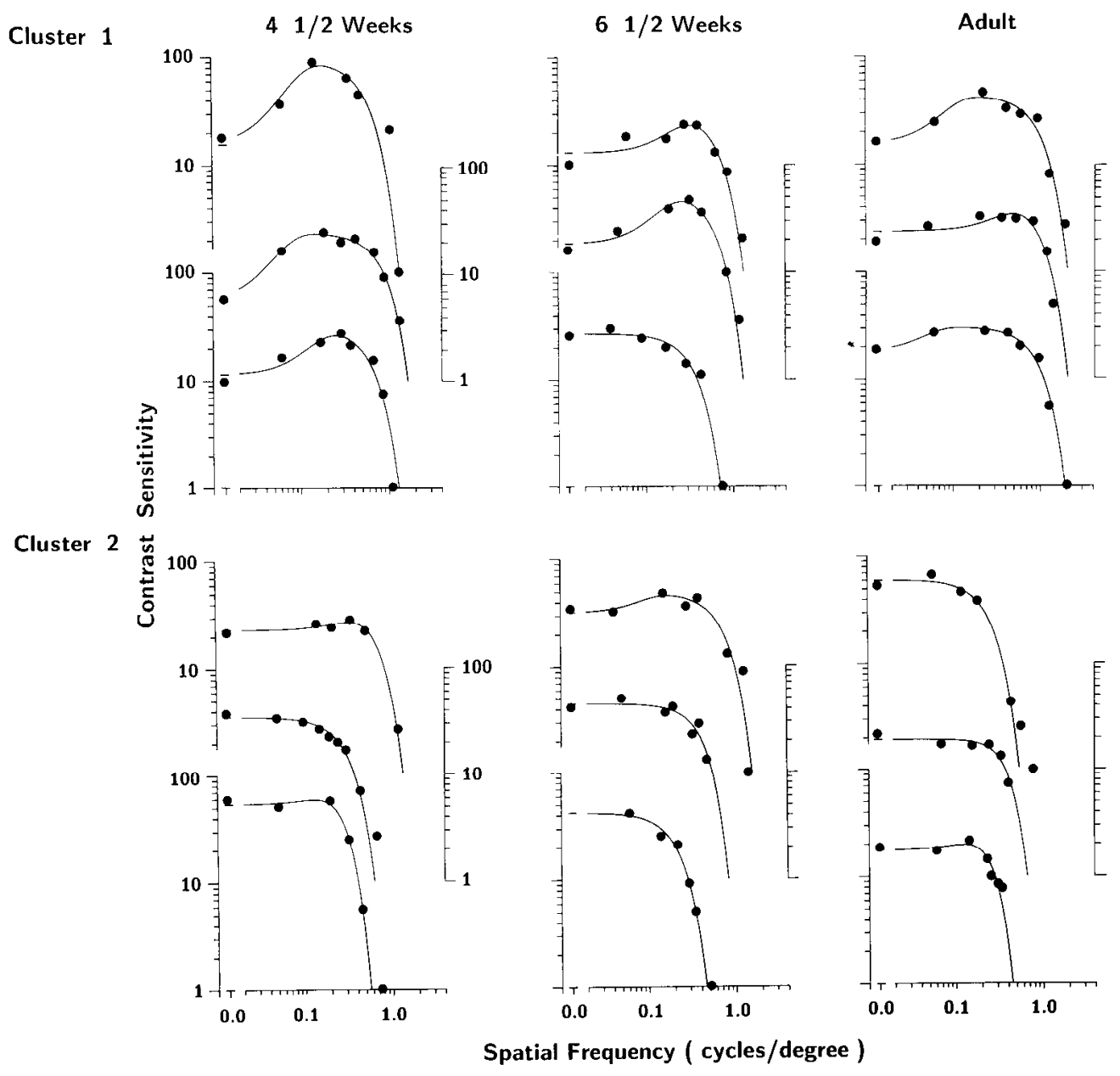

Spatial Frequency ( cycles/degree)
Thorn et al., 1976; Rusoff and Dubin, 1978). The increasing retinal magnification during growth reduces the degrees of visual angle subtended by a stimulus falling on a patch of retina of a given size (see Fig. $13, A, B)$. Therefore, we have analyzed developmental changes in spatial processing in a context relevant to the functional organization of the individual neuron within the expanding retinal milieu (millimeters of retinal extent). This calculation was accomplished by multiplying grating spatial frequencies in cycles/deg by scaling factors appropriate to the posterior nodal distances of the kitten and adult eyes in order to express spatial frequency in terms of cycles/ $\mathrm{mm}$ of retinal extent (Friedlander and Tootle, 1989). The scaling factors had the units deg/mm and were $6.71,6.21$, and 4.69 for the $41 / 2$-week-old, $61 / 2$-week-old, and adult groups, respectively.

Statistical comparisons. Unless otherwise indicated, statistical comparisons were made using a 2-tailed Mann-Whitney $U$ test.

\section{Results}

SCSFs werc mcasurcd for 83 retinal ganglion cell axons $(n=$ 27,28 , and 28 for the $4 \frac{1}{2} 2$ - and $6 \frac{1}{2}$-week-old kittens and aduit cats, respectively) and for 173 neurons in the $\mathrm{LGN}_{\mathrm{d}}$ A-layers ( $n$ $=79,59$, and 35 for the same respective ages). Quantitative analysis was conducted on the SCSFs of 169 cells (77 of the retinal ganglion cell axons and 92 of the $\mathrm{LGN}_{d}$ neurons) for which complete cell classification data were also available.

Examples of SCSFs of retinal ganglion cells and $\mathrm{LGN}_{\mathrm{d}}$ neurons at each age studied are shown in Figures 4 and 5 , respectively.
The data are representative and are shown separately for cells belonging to clusters 1 (X-) and 2 (Y-). Satisfactory fits by the difference of Gaussians model were obtained both for the retinal ganglion cells and $\mathrm{LGN}_{d}$ neurons at all ages studied. The average error per data point produced by the fitting procedure is presented in the legends of Figures 4 and 5. Qualitative inspection of Figure 4 reveals differences between the SCSFs of cells belonging to clusters $1(\mathrm{X}-)$ and $2(\mathrm{Y}$-) at each age, but little change across age. Retinal ganglion cells belonging to cluster $1(\mathrm{X}-)$ had relatively high spatial resolution and a significant decline in sensitivity at low spatial frequencies. Those belonging to cluster 2 (Y-) typically had relatively poor spatial resolution and little or no decline in sensitivity at low spatial frequencies. Similarities between cluster differences were observed for the SCSFs of $\mathrm{LGN}_{d}$ neurons, as is illustrated in Figure 5. As for the retinal ganglion cells, $L_{G N}$ neurons belonging to cluster $1(X-)$ tended to have relatively high spatial resolution and a decline in sensitivity at low spatial frequencies, while cluster 2 (Y-) $\mathrm{LGN}_{d}$ neurons had poor spatial resolution and little or no decline in sensitivity at low spatial frequencies. In contrast to the retinal ganglion cell data, however, 2 developmental changes are evident for the $\mathrm{LGN}_{\mathrm{d}}$ neurons: an increase in the incidence and amount of decrease in sensitivity at low spatial frequencies for clustcr 1 (X-) neurons and an apparent increase in spatial resolution for 


\section{LGNd NEURONS}

Cluster 1

Cluster 2
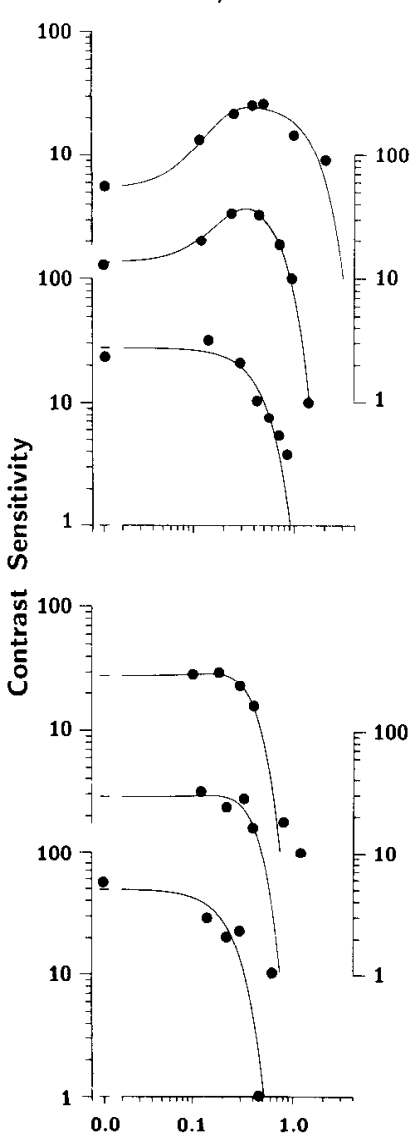

$61 / 2$ Weeks
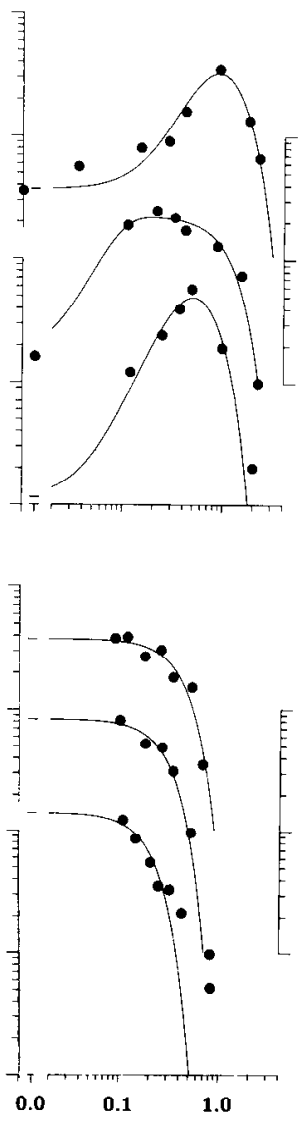
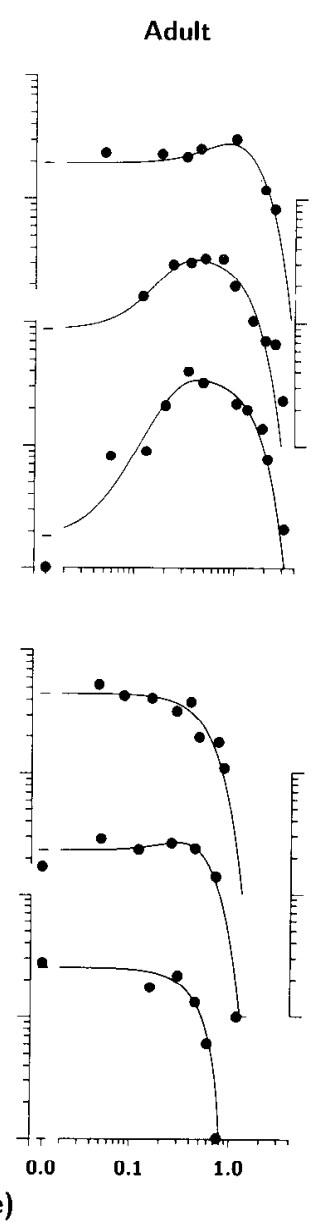

Figure 5. Example spatial contrast sensitivity functions of $\mathrm{LGN}_{\mathrm{d}}$ neurons from $4 \frac{1}{2}$ - and $6 \frac{1}{1}$-week-old kittens and adult cats with best least-squares fits assuming the difference of Gaussians model of the RF described in the text. Conventions are the same as in Figure 3. Median errors for the $\mathrm{LGN}_{\mathrm{a}}$ neurons in the $4 \frac{1}{2} 2$-week-old, $6 \frac{1}{2} 2$-week-old, and adult age groups, respectively, were 3.9 2.9 , and 3.1 for cluster $1(\mathrm{X}-)$ cells and $10.4,4.8$, and 13.0 for cluster $2(\mathrm{Y}-)$ cells. No significant age differences were observed in the size of the errors. However, in the adult the errors obtained for cluster 2 neurons were significantly greater than those obtained for cluster 1 neurons $(p<0.02)$. neurons in both clusters with increasing age. The development of these and other features of the SCSFs are examined quantitatively in the following sections.

\section{Spatial resolution}

The average spatial resolution of retinal ganglion cells and $L_{G N}$ neurons as a function of age is illustrated in Figure 6. The data are presented separately for neurons with RFs at eccentricities $\leq 10^{\circ}$ (Fig. 6, left) and with RFs at eccentricities $>10^{\circ}$ (Fig. 6, right). Those belonging to cluster $1(\mathrm{X}-)$ are indicated by open symbols and those to cluster $2(\mathrm{Y}-)$ by filled symbols. There was no significant change of spatial resolution with age for retinal ganglion cells in either cluster at eccentricities $\leq 10^{\circ}$ (Fig. $6 \mathrm{~A}$, left) in cycles $/ \mathrm{mm}$, but this finding must be viewed as tentative in light of the small sample size for this eccentricity range ( $n=$ 4,6 , and 3 for the $4 \frac{1 / 2}{2}$ and $61 / 2$-week-olds and adults, respectively). At $>10^{\circ}$ eccentricity, the cluster $2(\mathrm{Y}-$ ) retinal ganglion cells showed a small but significant worsening of spatial resolution from $4^{1 / 2}$ and $6^{1 / 2}$ postnatal weeks.

The spatial resolution of cluster $1(\mathrm{X}-)$ and cluster $2(\mathrm{Y}-) \mathrm{LGN}_{\mathrm{d}}$ neurons with RF eccentricities $\leq 10^{\circ}$ did not change significantly in terms of cycles/mm of retinal extent (Fig. $6 B$, left) during the period studied. The average spatial resolution of peripheral $L_{G N}$ neurons belonging to cluster 1 (X-) increased significantly between $4 \frac{1}{2}$ and $6^{1 / 2}$ weeks postnatally from 6.0 to 12.0 cycles/ $\mathrm{mm}$ (Fig. $6 \mathrm{~B}$, right). There was no change in the spatial resolution of cluster $2(\mathrm{Y}-) \mathrm{LGN}_{\mathrm{d}}$ neurons with peripheral RFs over the ages studied.

\section{Spatial frequency selectivity}

The spatial frequency selectivity of retinal ganglion cells and $\mathrm{LGN}_{\mathrm{d}}$ neurons is illustrated in Figure 7, which shows the proportion of cells with the bandwidths indicated on the abscissa. The 2 bars designated as low-pass indicate cells with some (left bar) or no low-frequency sensitivity loss. For both the retinal ganglion cells and $\mathrm{LGN}_{\mathrm{d}}$ neurons at all ages studied, cluster 2 $(\mathrm{Y}-)$ neurons behaved essentially as low-pass spatial frequency filters (Fig. 7, $A, B$, right). Similar observations have been made previously by others for retinal ganglion (Thibos and Levick, 1983) and $\mathrm{LGN}_{\mathrm{d}} \mathrm{Y}$-cells in older kittens and adult cats (Lehmkuhle et al., 1980; Mangel et al., 1983; Troy, 1983a) and support the argument that the neurons in cluster 2 are Y-cells at all ages studied. The spatial frequency filtering properties of retinal ganglion cells in cluster $1(\mathrm{X}-)$ appeared mature at all ages studied. The proportion of cluster 1 (X-) ganglion cells with bandpass properties remained constant at about 0.5 . Moreover, their average spatial frequency bandwidth was 4.2 octaves at $4 \frac{1}{2}$ and $61 / 2$ weeks postnatally and was not significantly different in the adult.

There was an increase in the proportion of $\mathrm{LGN}_{\mathrm{d}}$ neurons in 


\section{ECCENTRICITY $\leqslant 10^{\circ} \quad$ ECCENTRICITY $>10^{\circ}$}

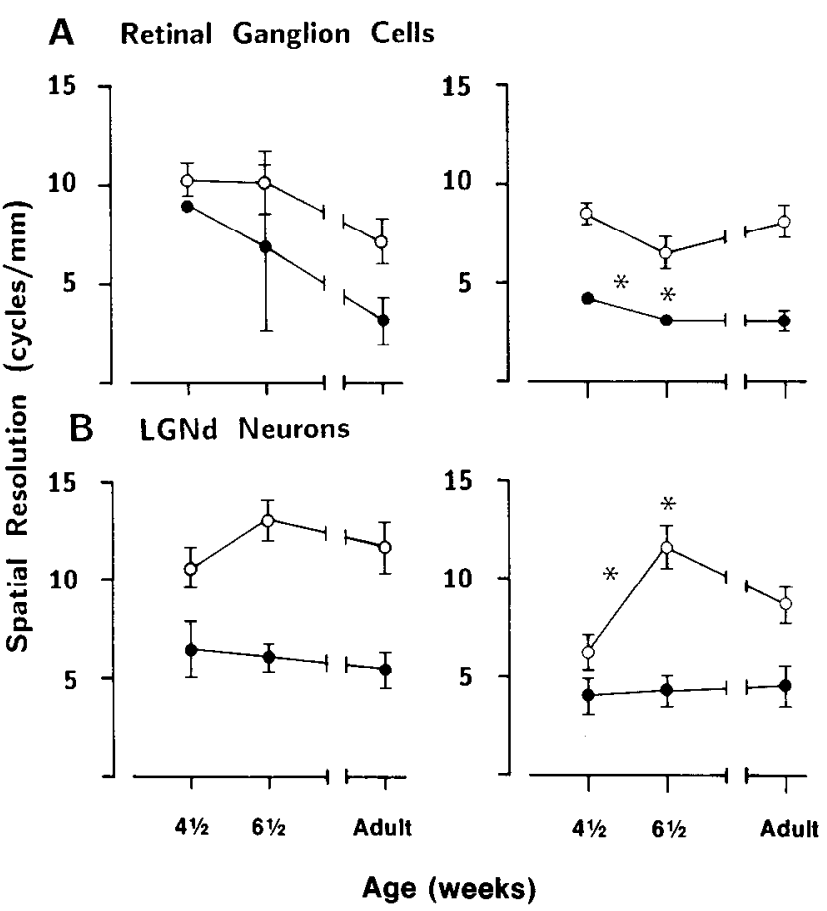

Figure 6. Mean spatial resolution in cycles $/ \mathrm{mm}$ of retinal ganglion cells $(A)$ and $\mathrm{LGN}_{\mathrm{d}}$ neurons $(B)$ with RFs located within the central $10^{\circ}$ of the visual field (left) or at greater eccentricities (right). Data are presented separately for cells belonging to clusters 1 (open symbols) and 2 (filled symbols) at the 3 ages tested. Asterisks between adjacent symbols indicate significant differences between adjacent age groups; asterisks directly over a symbol indicate significant differences between the 2 age groups flanking the age group under the symbol. Error bars indicate 1 $\mathrm{SE}$ of the mean. Sample sizes for calculation of the mean spatial res-

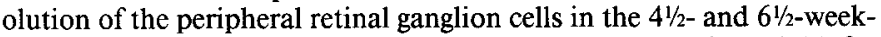
old and adult age groups were, respectively, $n=11,10$, and 11 for cluster 1 (X-) cells and $n=21,11$, and 15 for cluster $2\left(\mathrm{Y}^{-}\right)$cells. For the peripheral $\mathrm{LGN}_{\mathrm{d}}$ neurons the sample sizes for the same respective age groups were $n=14,4$, and 10 for cluster 1 cells and $n=4,10$, and 5 for cluster 2 cells.

cluster $1(\mathrm{X}-)$ that had spatial frequency bandpass properties from 0.45 at $4 \frac{1}{2}$ weeks postnatally to 0.80 in the $6 \frac{1}{1} 2$-week-old kittens and adult cats. This increase is statistically significant $\left(\chi^{2}, p<0.05\right)$ and indicates that the RF inhibitory surround mechanism of the cluster 1 (X-) $\mathrm{LGN}_{\mathrm{d}}$ neurons is maturing between $4 \frac{1 / 2}{2}$ and $6 \frac{1 / 2}{2}$ weeks postnatally. Intcrestingly, the spatial frequency $\mathrm{BW}$ of cluster $1(\mathrm{X}-) \mathrm{LGN}_{\mathrm{d}}$ neurons that could be classified as bandpass remained constant at about 3-3.5 octaves over the ages studied (Fig. $7 B$, left).

\section{Relationship between OSF and spatial frequency $B W$}

As is illustrated in Figure 8 , there was a significant inverse correlation between OSF and spatial frequency BW $(r=-0.68$, $p<0.003$, for all cells combined). The slope of the regression line of $\log$ BW on $\log$ OSF for all cells considered together was -0.32 . Comparable correlation coefficients and slopes were obtained separately for the retinal ganglion cells and $\mathrm{LGN}_{\mathrm{d}}$ neurons at all ages studied, suggesting no developmental trend in the relationship between the 2 parameters. This result implies that retinogeniculate neurons with different size RFs do not summate linearly over equal distances, i.e., do not have equal sized subre- gions (Robson, 1975), a situation that would yield a slope of -1.0 between BW and OSF. Rather, several populations of retinogeniculate neurons with different size RFs and summating areas (and spatial frequency bandpass tuning curves), which change little or not at all during the period studied, would account for the result (Tolhurst and Thompson, 1981; Kulikowski et al., 1982).

\section{Development of $R F$ size and sensitivity}

The development of the RF center size of retinal ganglion cells and $\mathrm{LGN}_{\mathrm{d}}$ neurons is examined in Figure 9, where the characteristic radius $\left(r_{c}\right)$ of the neurons is expressed in millimeters of retinal extent. There was no change across the ages studied in the RF center size of retinal ganglion cells belonging to cluster 1 (X-) (Fig. 9A). For cluster 1 (X-) retinal ganglion cells with RFs located within $10^{\circ}$ of the area centralis, the avęrage $r_{c}$ remained constant at about $0.06 \mathrm{~mm}$. The average $r_{c}$ of cluster 1 (X-) ganglion cells with more peripheral RFs was about 0.09 $\mathrm{mm}$ at all ages studied. There was a significant increase in the RF center size of cluster 2 (Y-) retinal ganglion cells with RFs located beyond $10^{\circ}$ from the area centralis between $4 \frac{1}{2}$ and $6 \frac{1}{2}$ weeks postnatally, where $r_{c}$ increased from about 0.13 to 0.20 $\mathrm{mm}$. The average RF size of cluster 2 (Y-) ganglion cells with peripheral RFs increased further to $0.29 \mathrm{~mm}$ between $6 \frac{1}{2}$ postnatal weeks and adulthood, but this increase fell short of statistical significance. Since RF center size has been adjusted for retinal image size in these calculations, this result implies that there is an increased functional convergence from more distal retinal neurons onto cluster $2\left(\mathrm{Y}_{-}\right)$retinal ganglion cells during postnatal development.

The development of the RF center size of A-layer $\mathrm{LGN}_{d}$ neurons is examined in Figure $9 B$. The average RF center size of cluster 1 (X-) LGN ${ }_{d}$ neurons with RFs located within $10^{\circ}$ of the area centralis decreased from about 0.08 to $0.05 \mathrm{~mm}$ between $4 \frac{1}{2}$ weeks postnatally and adulthood. This decrease was not statistically significant. There was, however, a significant decrease in $r_{c}$ for cluster $1(\mathrm{X}-) \mathrm{LGN}_{\mathrm{d}}$ neurons with more peripheral RFs between $4 \frac{1 / 2}{2}$ and $6 \frac{1 / 2}{2}$ weeks postnatally, from 0.12 to 0.05 $\mathrm{mm}$.

The development of the peak sensitivity $\left(k_{c}\right)$ of the RF center mechanism of retinogeniculate neurons is examined in Figure 10. There was a significant decrease in the average value of $k_{c}$ for retinal ganglion cells belonging to cluster 2 (Y-) from $4 \frac{1}{2}$ weeks postnatally to adulthood (Fig. 10). This decrease is complementary to the significant increase in $r_{c}$ for cluster $2(\mathrm{Y}-)$ ganglion cells that was described above. The peak center sensitivity of cluster $1(\mathrm{X}-)$ retinal ganglion cells did not change significantly over the ages studied. There was a significant increase in $k_{c}$ for cluster $1(\mathrm{X}-) \mathrm{LGN}_{\mathrm{d}}$ neurons between $4 \frac{1}{2}$ and $6 \frac{1}{2}$ weeks postnatally, but the increase between $6 \frac{1 / 2}{2}$ weeks and adulthood was not statistically significant. For cluster 2 (Y-) $\mathrm{LGN}_{\mathrm{d}}$ neurons the average $k_{c}$ was significantly poorer at $4^{1 / 2}$ weeks postnatally than in adulthood, primarily as a result of a significant increase in its value between $6 \frac{1 / 2}{\text { wccks postnatally }}$ and adulthood.

The development of the size and sensitivity of the RF surround mechanism of retinogeniculate neurons was also examined. There were no clear trends in the development of $r_{s}$ and $k_{s}$ for either the retinal ganglion cells or $\mathrm{LGN}_{\mathrm{d}}$ neurons. There was great variability in the size and sensitivity of the RF surround at each age studied, and no significant difference in $r_{s}$ between any age groups was observed. 
A Retinal Ganglion Cells

$41 / 2$ weeks

$61 / 2$ weeks

adult
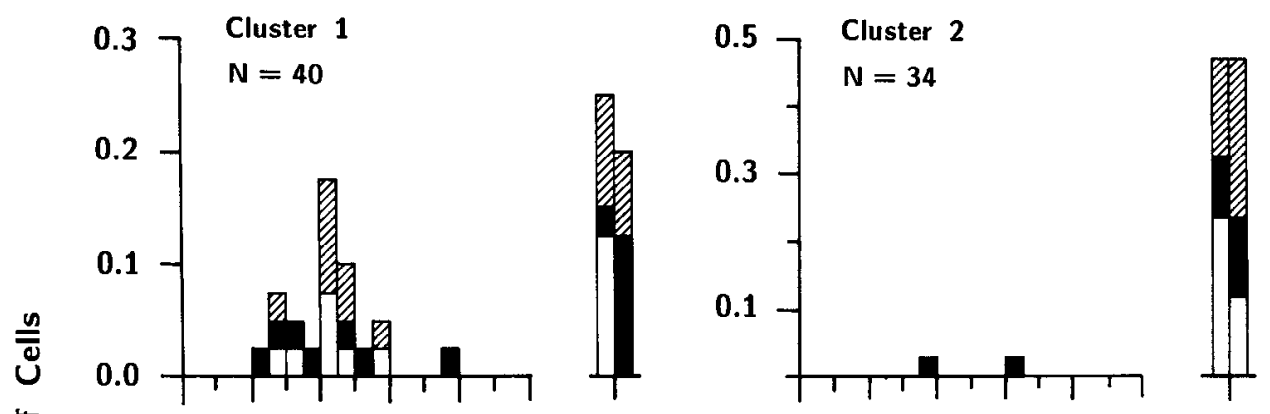

to

\section{¿ B LGNd Neurons}

2.0

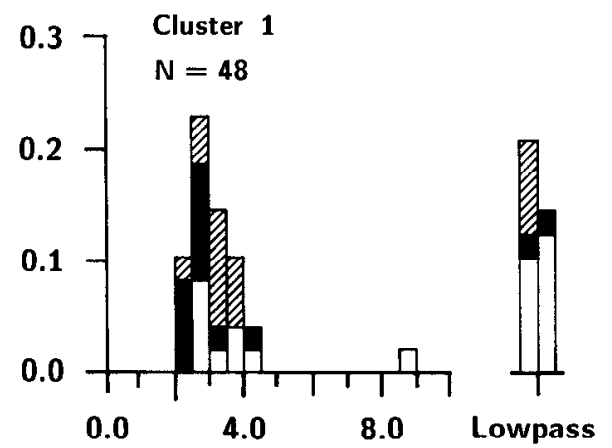

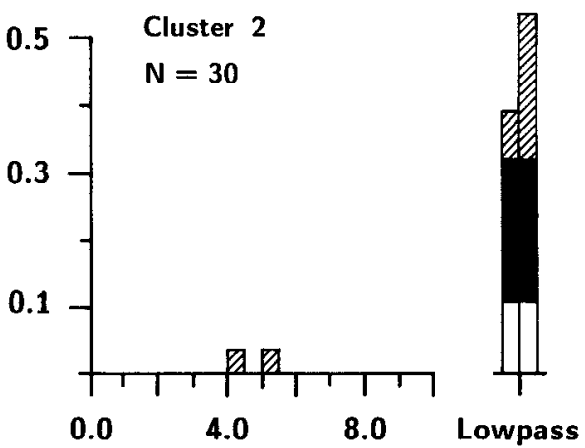

Bandwidth (Octaves)
Figure 7. Spatial frequency BWs of retinal ganglion cells $(A)$ and $\mathrm{LGN}_{\mathrm{d}}$ neurons $(B)$ belonging to clusters $1(\mathrm{X}$-) and $2(\mathrm{Y}-)$ at each age studied. The ordinate indicates the proportion of the $\mathrm{N}$ cells with a given bandwidth. Cells designated as low-pass are graphed in the rightmost 2 bins and consisted of cells with no low-frequency roll-off in sensitivity (rightmost bin) and cells that had a low-frequency sensitivity decline that was less than $0.3 \log$ units below the peak. Note the lack of cluster 2 neurons with spatial bandpass properties.

\section{Retinal Ganglion Cells \\ LGNd Neurons 0}

\section{Relationship between parameters}

In the adult cat, Linsenmeier et al. (1982) found a strong inverse relationship between RF center size $\left(r_{c}\right)$ and peak sensitivity $\left(k_{c}\right)$ of retinal ganglion cells. In the present study we have replicated their finding and extended the result to developing ganglion cells and $\mathrm{LGN}_{\mathrm{d}}$ neurons. The data are presentcd in Figurc $11 \mathrm{~A}$, where it can be seen there is a high $(r=-0.88)$ correlation between logarithms of the center radius and peak sensitivity of the retinogeniculate neurons at all ages studied. The equation of the regression line is $\log \left(k_{c}\right)=-1.38 \log \left(r_{c}\right)+1.31$, and the agreement with the results of Linsenmeier et al. (1982) is striking. Furthermore, performing the regression analysis separately on the retinal ganglion cells and $\mathrm{LGN}_{\mathrm{d}}$ neurons at each age studied yielded comparable results. These findings imply that the mechanism governing light adaptation of the center of the RF is already mature by $4 \frac{1}{2}$ weeks postnatally.

A second relationship between the parameters of the Gaussian model that appeared to be the same in the neonate and adult was the relative independence of center and surround size (Fig. $11 B)$. For both the retinal ganglion cells and $\mathrm{LGN}_{\mathrm{d}}$ neurons surround radius $\left(r_{s}\right)$ was poorly correlated with center size $\left(r_{c}\right)$ at all ages studied. Neurons belonging to cluster $2(\mathrm{Y}-)$ tended to constitute an exception to this generalization, however. This was due to cluster $2(\mathrm{Y}-)$ neurons with no low spatial frequency sensitivity loss, which had center and surround mechanisms with comparable sizes.

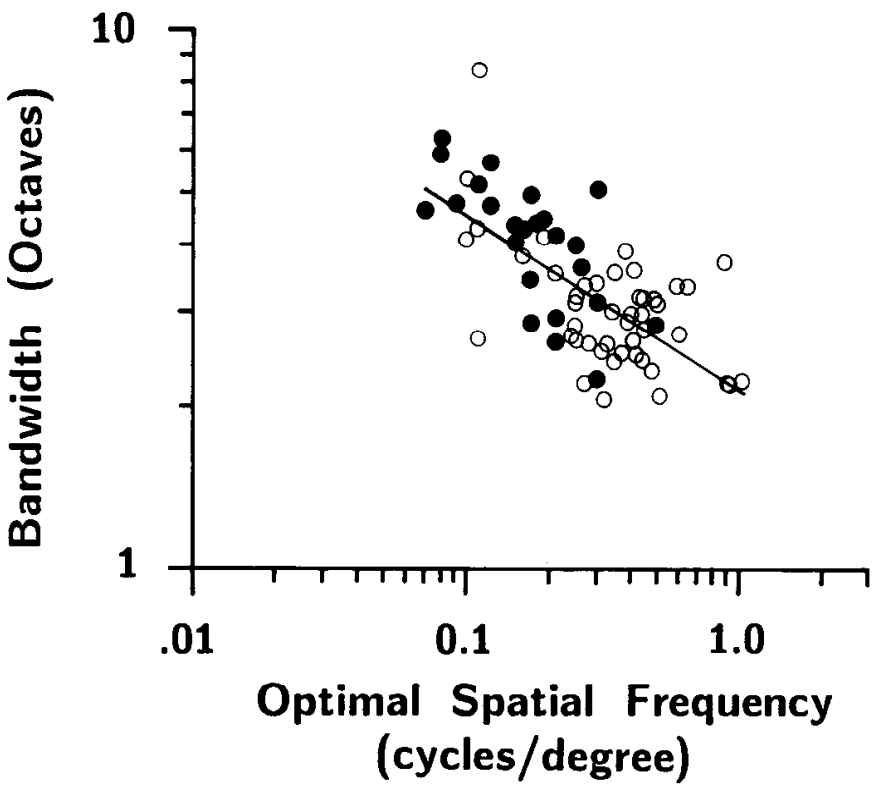

Figure 8. BWs of retinal ganglion cells (filled symbols) and $\mathrm{LGN}_{\mathrm{d}}$ neurons (open symbols) plotted as a function of their optimal spatial frequency. The data are for all cells with bandpass properties regardless of postnatal age. The correlation of coefficient is -0.68 and the best-fit least-squares regression line has the equation $\log (\mathrm{BW})=-1.32 \mathrm{log}$ (spatial frequency) +0.34 . 
A Retinal Ganglion Cells

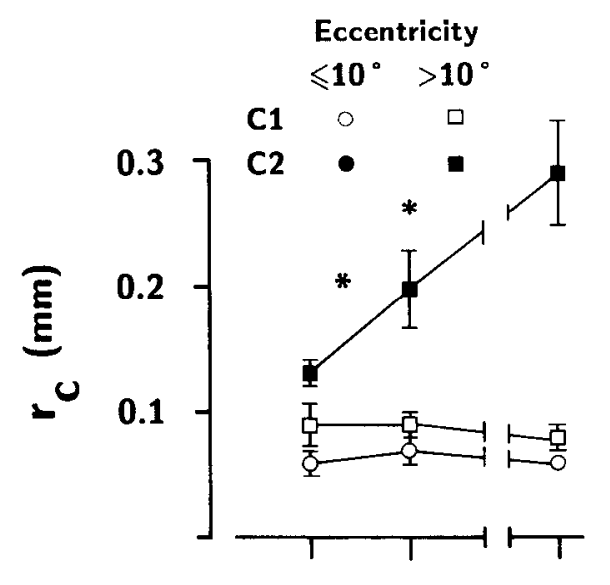

B LGNd Neurons

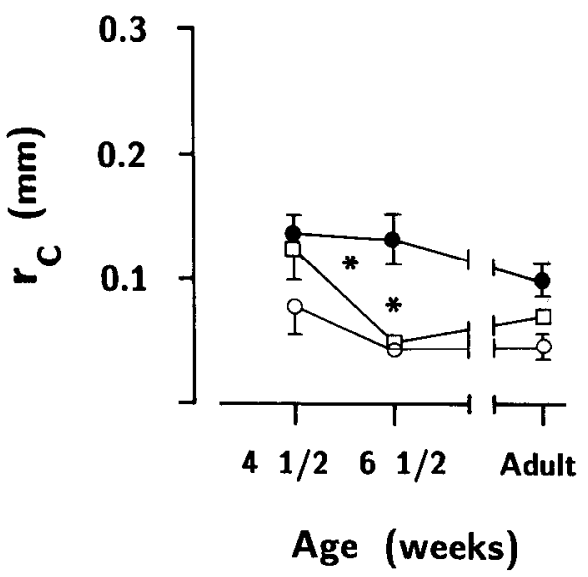

Figure 9. Mean values of the characteristic centcr radius $\left(r_{c}\right)$ of rctinal ganglion cells $(A)$ and $\mathrm{LGN}_{\mathrm{d}}$ neurons $(B)$ with RFs within $10^{\circ}$ of the area centralis (circles) or at eccentricities $>10^{\circ}$ (squares). Other conventions are the same as in Figure 6.

\section{Surround development}

The development of the strength of the RF inhibitory surround mechanism was examined with 2 measures in addition to simple derivation of $r_{s}$ and $k_{s}$. The first measure was the ratio of the integrated volumes of the RF surround and center mechanisms $\left(\mathrm{Vol}_{\mathrm{sc}}\right.$ ), which is given by (Linsenmier et al., 1982) as

$$
\mathrm{Vol}_{\mathrm{sc}}=k_{s} r_{s}^{2} / k_{c} r_{c}^{2} \text {. }
$$

$\mathrm{Vol}_{\mathrm{sc}}$ gives the predicted response of a neuron to a stimulus that completely fills both the center and surround regions. Thus, it is a measure of the surround mechanism's ability to inhibit the neuron's response to large (low spatial frequency) stimuli. The second, comparable measure was the contrast sensitivity ratio, which was quantified as the ratio of the contrast sensitivity at a spatial frequency $0.63 \mathrm{log}$ units below optimal spatial frequency to the peak sensitivity.

The development of the strength of RF surround inhibition is illustrated in Figure 12, where the relative volumes of RF surround and center mechanisms and the contrast sensitivity ratio are plotted for the retinal ganglion cells and $\mathrm{LGN}_{\mathrm{d}}$ neurons at each age studied. There was no significant change across the ages studied for retinal ganglion cells belonging to clusters 1

\section{A Retinal Ganglion Cells}

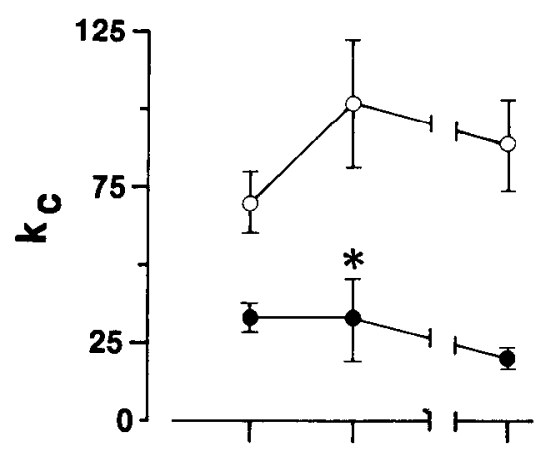

B LGNd Neurons

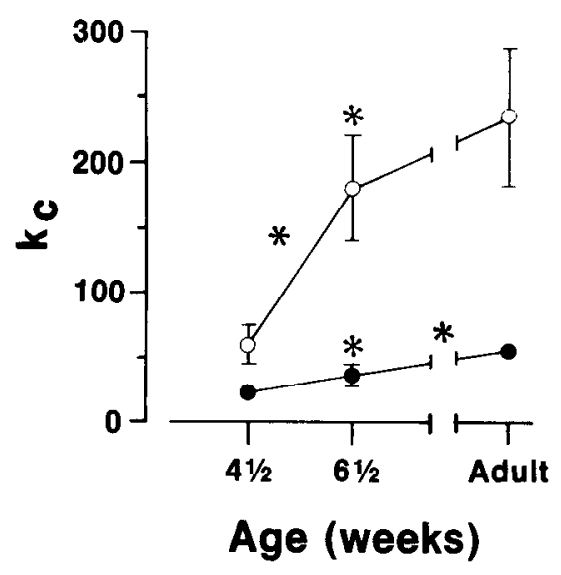

Figure 10. Mean values of the peak sensitivity $\left(k_{c}\right)$ of the center mechanisms of retinal ganglion cells and $\mathbf{L G N}_{d}$ neurons belonging to clusters 1 (open symbols) and 2 (closed symbols) at each age studied. Other conventions are as in Figure 6.

(X-) or $2(\mathrm{Y}-)$. The average relative volume of the surround and center mechanisms of cluster 1 (X-) ganglion cells was about 0.65 at $4 \frac{1}{2}$ weeks postnatally and in the adult. The low value of 0.50 for cluster $1\left(\mathrm{X}\right.$-) ganglion cells at $6 \frac{1}{2}$ weeks postnatally is unexpected, but is not significantly different from the other ages. For cluster 2 (Y-) ganglion cells the average relative volumes of the 2 RF mechanisms remained constant at about 0.50 across all ages studied. Thus, the relative strength of the RF surround mechanism for retinal ganglion cells belonging to both clusters $1(\mathrm{X}-)$ and $2(\mathrm{Y}-)$ appears mature as early as $4 \frac{1}{2}$ weeks postnatally. There was a significant increase in the strength of the RF surround mechanism for $\mathrm{LGN}_{\mathrm{d}}$ neurons belonging to cluster 1 between $4 \frac{1}{2}$ and $6 \frac{1}{2}$ weeks postnatally. The relative surround to center volume of cluster $1(\mathrm{X}-) \mathrm{LGN}_{\mathrm{d}}$ neurons increased from 0.57 at $4 \frac{1 / 2}{2}$ weeks postnatally to 0.85 at $61 / 2$ weeks postnatally and was 0.81 in the adult. The relative surround to center volume of cluster $2(\mathrm{Y}-) \mathrm{LGN}_{\mathrm{d}}$ neurons did not change significantly across the ages studied, although there was a slight decrease from an average value of 0.53 at $4 \frac{1}{2}$ weeks postnatally to 0.36 in the adults. Interestingly, the relative surround to center strength of cluster $1(\mathrm{X}-) \mathrm{LGN}_{\mathrm{d}}$ neurons did not differ significantly from that of $\mathrm{LGN}_{\mathrm{d}}$ neurons in cluster $2(\mathrm{Y}-)$ at $4 \frac{1}{2}$ weeks postnatally but was greater for cluster 1 (X-) neurons in the older animals. This, and the greater surround strength of cluster $1(\mathrm{X}-)$ LGN $_{\mathrm{d}}$ neurons vis-à-vis cluster 1 (X-) retinal ganglion cells at ages greater than $4 \frac{1}{2}$ weeks, suggests that this 
A
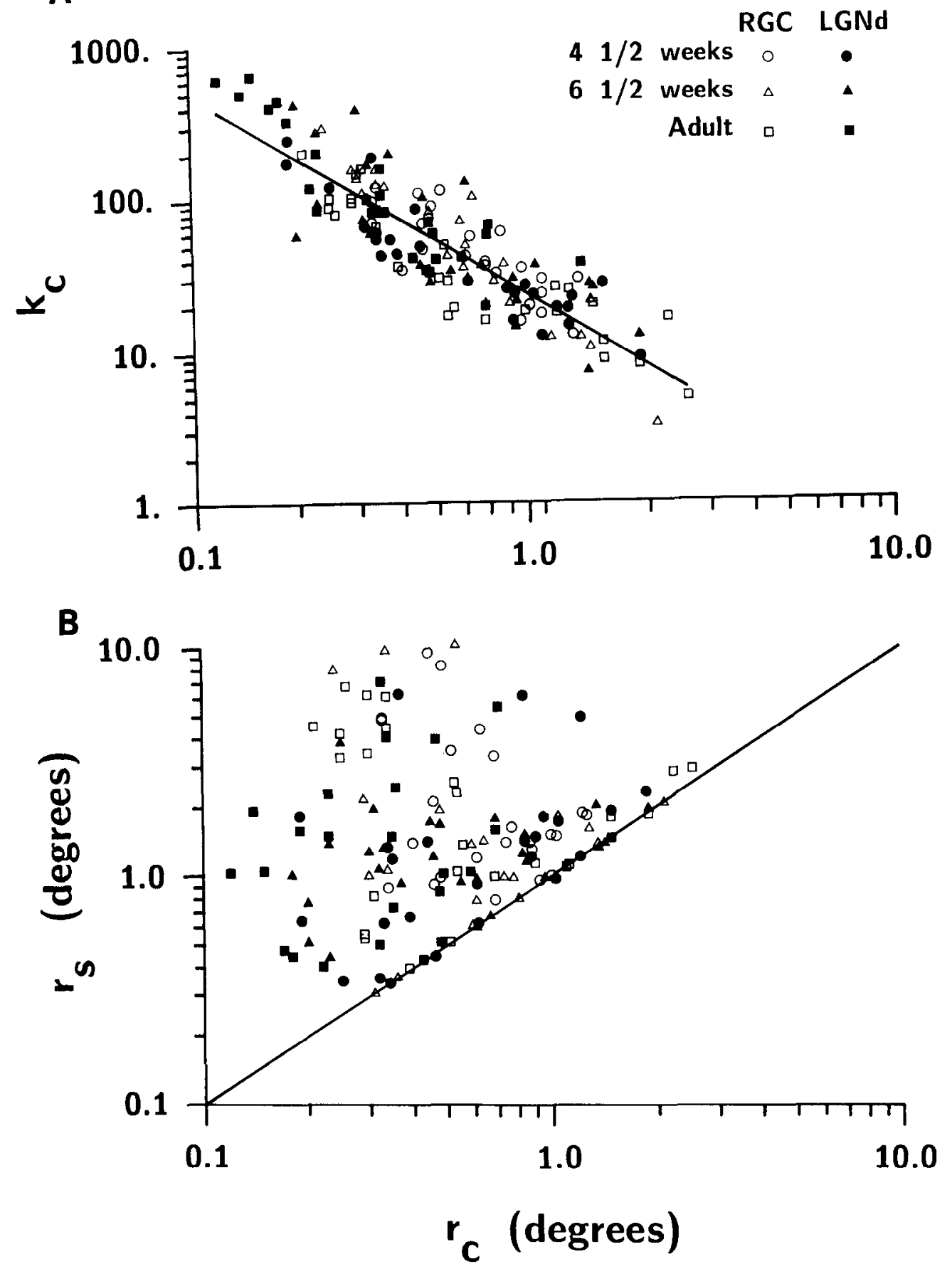

Figure 11. A, Scatter plot of peak center sensitivity $\left(k_{c}\right)$ as a function of characteristic center radius $\left(r_{c}\right)$ for retinal ganglion cells (open symbols) and $\mathrm{LGN}_{\mathrm{d}}$ neurons (filled symbols) at each age studied. The correlation coefficient between the 2 parameters is -0.88 and the regression line has the equation $\log \left(k_{c}\right)=-1.38 \log \left(r_{c}\right)+1.31 . B$, Scatter plot of characteristic surround radius $\left(r_{s}\right)$ as a function of center radius $\left(r_{c}\right)$ for retinal ganglion cclls (open symbols) and $\mathrm{LGN}_{\mathrm{d}}$ neurons (filled symbols) at each age studied. Along the diagonal line $r_{s}=r_{c}$. Note the lack of significant correlation between $r_{s}$ and $r_{c}$.

increasing inhibitory surround strength of cluster $1(\mathrm{X}-) \mathrm{LGN}_{\mathrm{d}}$ neurons is due to the maturation of intrageniculate inhibitory processes. The contrast sensitivity ratio measure of RF surround strength (Fig. 12, right) mirrors in every instance the results obtained with the $\mathrm{Vol}_{\mathrm{sc}}$ measure. The average value of the ratio remains constant across the ages studied at about 0.55 and 0.85 , respectively, for retinal ganglion cells belonging to clusters 1 (X-) and $2(\mathrm{Y}-)$. For the $\mathrm{LGN}_{\mathrm{d}}$ neurons in cluster 1 (X-), there is a significant decrease in the contrast sensitivity ratio from 0.60 to 0.30 between $4 \frac{1}{2}$ to $61 / 2$ weeks postnatally, indicating an increase in the strength RF surround inhibition. For $L_{G N} N_{d}$ neurons in cluster $2(\mathrm{Y}-)$ the average value of the ratio was about 0.85 at all ages studied.

\section{Discussion}

Development of spatial contrast sensitivity

The spatial contrast sensitivity of retinal ganglion cell axons is already adult-like in many respects by $4 \frac{1}{2}$ weeks postnatally. When the spatial frequency of grating stimuli is expressed in cycles/mm of retinal extent, thereby eliminating changes in the size of the retinal image as a factor, the spatial resolution of cluster $1\left(\mathrm{X}\right.$-) ganglion cells is the same at $4 \frac{112}{2}$ and $61 / 2$ weeks postnatally as in adulthood. Neither does the spatial frequency selectivity of the retinal ganglion cells change during the period studied. Both the proportion of cells with bandpass properties and the average spatial frequency $\mathrm{BW}$ were the same for neonatal 


\section{A Retinal Ganglion Cells}
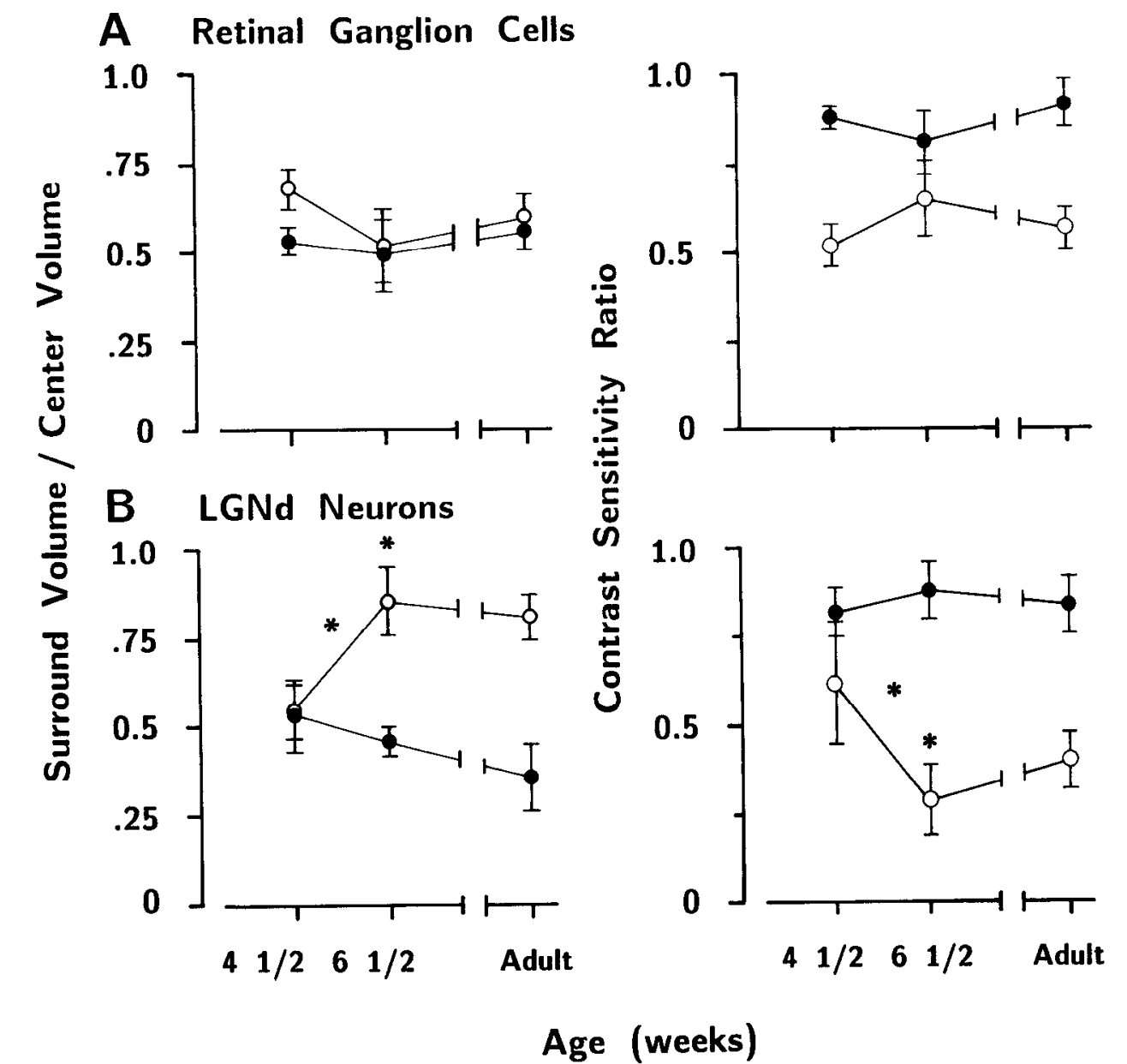

Figure 12. Relative integrated strengths of the RF surround and center mechanisms and the contrast sensitivity ratio of retinal ganglion cells $(A)$ and $\mathrm{LGN}_{\mathrm{d}}$ neurons $(B)$ of $41 / 2$ - and $6^{1 / 2}$-weekold kittens and adult cats. The data are illustrated separately for cells belonging to clusters 1 (open symbols) and 2 (filled symbols). Other conventions are the same as in Figure 6. and adult retinal ganglion cells. The RF inhibitory surround strength of cluster 1 (X-) and cluster 2 (Y-) ganglion cells also appears mature by $4 \frac{1}{2}$ weeks postnatally, as cvidenced by a comparable degree of reduction in contrast sensitivity at low spatial frequencies at all ages tested. A similar conclusion regarding the inhibitory surround strength of ganglion cells in 3-week-old kittens was reached by Hamasaki and Flynn (1977) using different techniques.

An exception to the generally mature picture presented by the retinal ganglion cells was the significant worsening of the spatial resolution of cluster $2\left(\mathrm{Y}_{-}\right)$cells with peripheral RFs between $4 \frac{1}{2}$ and $6^{1 / 2}$ weeks postnatally. This degradation of acuity, which was maintained into adulthood, was apparent only when spatial frequency was scaled to account for changes in the retinal image size between different ages. That is, the spatial resolution of the peripheral cluster 2 ganglion cells did not change during the period studied in terms of cycles/deg of visual angle. Thus, in terms of its significance for behavior, the acuity of the peripheral $\mathrm{Y}$-system is mature by $4 \frac{1}{2}$ weeks postnatally. However, when viewed as the ability to resolve gratings in terms of spatial frequency on the retina, there is a developmental loss of "neural acuity" for the peripheral Y-retinal ganglion cells.

Compared with the retinal ganglion cell axons, significant immaturities in processing capacities for spatial contrast patterns are observed for neonatal neurons in the $\mathrm{LGN}_{d}$ A-layers. The average spatial resolution of cluster $1(\mathrm{X}-) \mathrm{LGN}_{\mathrm{d}}$ neurons is poorer at $4 \frac{1}{2} 2$ weeks postnatally, both for cells with centrally and peripherally located RFs, than at $6^{1 / 2}$ weeks postnatally and in the adult. The increase in spatial resolution of cluster $1 \mathrm{LGN}_{d}$ neurons with centrally located RFs (in terms of degrees of visual angle but not millimeters of retinal extent) from 1.5 to 2.0 cycles/ deg between $4 \frac{1 / 2}{2}$ and $6 \frac{1 / 2}{2}$ weeks postnatally is in good agreement with the results obtained by Ikeda and Tremain (1978) for sustained $\mathrm{LGN}_{\mathrm{d}}$ cells with RFs near the area centralis. However, scaling for retinal image size reveals that the developmental improvement of spatial resolution for cluster $1(\mathrm{X}-) \mathrm{LGN}_{d}$ cells with central RFs is due simply to growth of the eye. The improved spatial resolution observed for peripheral cluster 1 (X-) cells hetween $4 \frac{1}{2}$ and $6 \frac{1}{2}$ weeks postnatally persists after scaling for eye size and therefore has a neural maturation component. In the present study, the spatial resolution of $\mathrm{LGN}_{\mathrm{d}}$ neurons belonging to cluster $2\left(\mathrm{Y}_{-}\right)$was observed not to change significantly between $4 \frac{1}{2}$ weeks postnatally and adulthood. Mangel et al. (1983) made the same observation for the linear response component of $\mathrm{LGN}_{\mathrm{d}} \mathrm{Y}$-cells in kittens aged 8 weeks and older. Wilson et al. (1982) observed a significant increase in the spatial resolution of the nonlinear component of Y-cells in the medial interlaminar nucleus of kittens of comparable ages. These observations are particularly interesting in light of the increased resolution observed for cluster $1(\mathrm{X}-)$ retinal ganglion cells and $\mathrm{LGN}_{\mathrm{d}}$ neurons during the same period and provide support for the hypothesis that the nonlinear subunit of the $Y$ (cluster 2) cell has its origin in the $\mathrm{X}$-cell pathway (So and Shapley, 1979). 


\section{Cluster 1 (X-) Cells RF Eccentricity $>10^{\circ}$ Kitten}
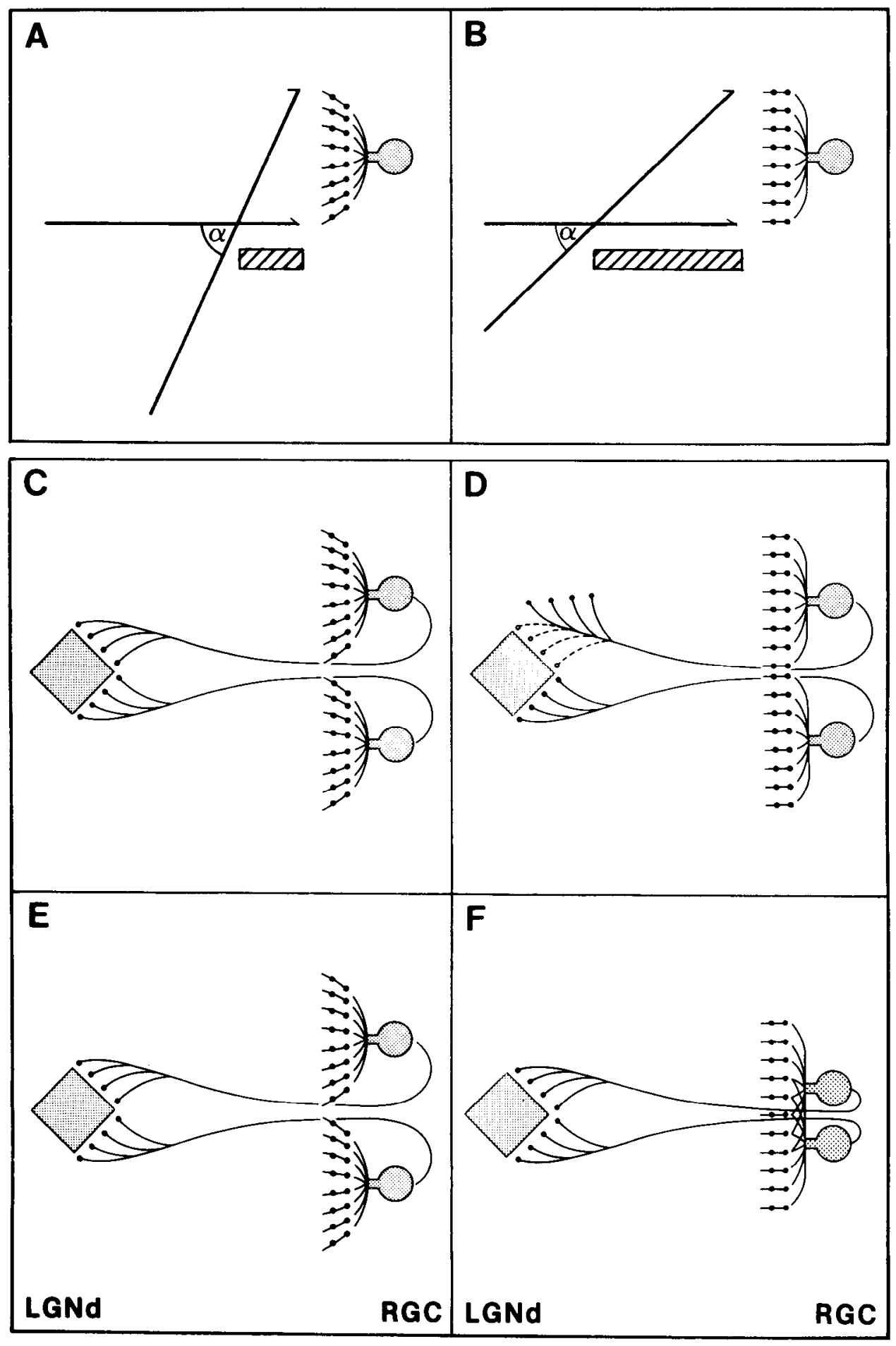

Figure 13. Schematic diagrams illustrating hypothesized mechanisms underlying the constant RF center size of peripheral cluster $1(\mathrm{X}-)$ retinal ganglion cells $(A, B)$ and the developmental reduction in the RF center size of peripheral cluster $1 \mathrm{LGN}_{\mathrm{d}}$ neurons $(C-F)$ observed in the present study. Peripheral cluster 1 ganglion cells from kitten $(A)$ and adult $(B)$ retina are shown to receive input from the receptor-bipolar cell (filled circles) pathway over the same size patch of retina. However, because the dendritic spread of the beta cells is only about $70 \%$ of the adult size at 4 weeks postnatally (Rusoff and Dubin, 1978), greater convergence onto the ganglion cell is evident for the kitten. Although the spatial extent of the receptor-bipolar input is the same at the 2 ages, the angular extent ( $\alpha$; in deg) of the RF field of the kitten ganglion cell is greater than that of the adult-as a result of the longer posterior nodal distance of the adult eye (hatched har). $C$ and $D$, One hypothesized mechanism producing smaller RF center sizes for peripheral cluster $1 \mathrm{LGN}_{\mathrm{d}}$ neurons (diamonds) in adult animals. In $C$, the kitten $\mathrm{LGN}_{d}$ neuron receives convergent synaptic input from 2 ganglion cells. During development, the synaptic input from the upper ganglion cell is lost by physical retraction of the contacts (upturned solid lines; Sur et al., 1984) or by a mechanism that leaves the synaptic contacts in place but renders them functionally nonsignificant (dotted lines). In an alternative scheme $(E, F)$, smaller $\mathrm{RF}$ center sizes for adult $\mathrm{LGN}_{\mathrm{d}}$ neurons are a result not of reduced functional convergence from the ganglion cells, but from increased overlap of neighboring ganglion cell dendrites in the adult.
The RF inhibitory surround mechanism of cluster 1 (X-) LGN $_{d}$ cells is also immature at $4 \frac{1}{2} 2$ weeks postnatally. There is a reduced proportion of cells with spatial bandpass properties, a significantly lower ratio of surround to center volume, and a smaller decline in contrast sensitivity at low spatial frequencies for cluster $1\left(\mathrm{X}_{-}\right) \mathrm{LGN}_{\mathrm{d}}$ cells at this age than for older kittens and adult cats. We also observed weak RF inhibitory surrounds for kitten $\mathrm{LGN}_{d}$ neurons using a technique employing suprathreshold stimuli in a previous study (Tootle and Friedlander, 1986). Our data suggest that the weaker RF surrounds of the $\mathrm{LGN}_{\mathrm{d}}$ cluster $1(\mathrm{X}-)$ cells is due to an immaturity of intrageniculate inhibitory processes. The strength of the inhibitory surrounds of the retinal ganglion cells and $\mathrm{LGN}_{\mathrm{d}}$ neurons in cluster 1 (X-) did not differ at 41/2 weeks postnatally. However, 
surround strength was significantly greater for the $\mathrm{LGN}_{\mathrm{d}}$ neurons than for the retinal ganglion cells at $6 \frac{1 / 2}{2}$ weeks postnatally and in adulthood. Since the strength of the inhibitory surrounds of cluster $1(\mathrm{X}-)$ retinal ganglion cells was unchanged during this period, the difference was due solely to an increase in the strength of the surrounds of the $\mathrm{LGN}_{\mathrm{d}}$ neurons.

The inhibitory synaptic circuitry of the $\mathrm{LGN}_{\mathrm{d}}$ is undergoing rapid maturation during the period in which we have observed increases in the strength of the RF surround of $\mathrm{LGN}_{d}$ neurons. For example, there is a marked increase in the number of the presumptive inhibitory F-synaptic profiles within the synaptic glomeruli between 30 and $50 \mathrm{~d}$ postnatally (Winfield and Powell, 1980; Winfield et al., 1980). Maturation of the ultrastructural features of $\mathrm{LGN}_{d}$ synaptic circuitry is accompanied by an increased staining for glutamic acid decarboxylase (Shotwell et al., 1986), the synthetic enzyme for the inhibitory transmitter GABA and by increased effectiveness of the GABA blocker bicuculline in altering contrast-response functions of $\mathrm{LGN}_{d}$ neurons (Berardi and Morrone, 1984). These structural and chemical developments provide a likely basis for the increase in the RF inhibitory surround strength observed between $4 \frac{1}{2}$ and $61 / 2$ weeks postnatally.

\section{Development of spatial frequency selectivity}

The spatial frequency selectivity of the retinal ganglion cells appears mature at the earliest age (41/2 weeks postnatally) examined in the present study, both in terms of average BW and in the proportion of cells with spatial frequency bandpass properties. The proportion of cluster 1 (X-) $\mathrm{LGN}_{\mathrm{d}}$ neurons with bandpass properties increases significantly between $4 \frac{1}{2}$ and $6 \frac{1}{2}$ weeks postnatally. However, the spatial frequency BW of $\mathrm{LGN}_{d}$ neurons with bandpass properties does not change between these ages. Thus, there is an increase in the spatial frequency selectivity of the $\mathrm{LGN}_{\mathrm{d}}$ output to the visual cortex, in terms of the number of selective cells (but not in their spatial frequency BWs). Interestingly, similar changes have been observed in the development of the spatial frequency selectivity of striate cortical neurons. Derrington and Fuchs (1981) and Derrington (1984) report little change in the average spatial frequency BW of kitten cortical neurons after 3 weeks postnatally. These authors did observe, however, an increase in the proportion of cortical cells with bandpass properties between 4 and 5-7 weeks postnatally. This increase may reflect, in part, an increased number of $L_{G N}{ }_{d}$ afferent neurons with spatial bandpass properties; but more narrow BWs and a higher proportion of selective cells are observed among the cortical neurons, indicating an intracortical contribution to their spatial frequency selectivities.

\section{Applicability of the DOG model in the kitten}

Although the differences of Gaussians model has been applied successfully in previous studies of retinal ganglion cells (EnrothCugell and Robson, 1966; Linsenmeier et al., 1982) and LGN neurons (So and Shapley, 1981) in adult cats, the present study represents the first test of its applicability to developing retinogeniculate neurons. If the RF sensitivity profiles of kitten cells deviated significantly from a Gaussian distribution, then one would expect poorer fits of the model to the data from the young animals. We found that the averaged squared error obtained in fitting the model to spatial contrast sensitivity data from the youngest animals in the present study did not differ significantly from that produced by fits to data from adult animals. Thus, our data suggest the application of the DOG model is appropriate in the retinogeniculate system of the neonatal kitten.

\section{$R F$ development}

The present results are in general agreement with those of previous studies (Rusoff and Dubin, 1977; Hamasaki and Sutija, 1979) in that the RF organization of the retinal ganglion cells appears largely mature by 4-5 weeks postnatally. An exception, however, is the observed increase in RF center size of peripheral cluster 2 (Y-) ganglion cells during postnatal development. The structural basis for this increase in RF center size might be (1) growth of $\alpha$-cell (Peichl and Wassle, 1981; Saito, 1983) dendritic arbors and/or (2) increased functional convergence from bipolar and amacrine cells (Freed and Sterling, 1988). Since the dendritic field sizes of the $\alpha$-ganglion cells are already adult-like by $15 \mathrm{~d}$ postnatally (Dann et al., 1987, 1988), the latter mechanism appears to be more likely.

The cluster $1(\mathrm{X}-)$ retinal ganglion cells show no change in their RF size in retinal extent from 4 postnatal weeks. The development of the RF center for these cells is summarized schematically in Figure $13, A, B$. By virtue of the growth of the eye [and thus decreasing angle $\alpha$ (see Fig. 13 legend)], the RF center decrcases in sizc in tcrms of degrees of visual angle but maintains constancy in terms of retinal extent. These findings are compatible with the available anatomical data demonstrating postnatal growth of the dendritic arbors of peripheral $\beta$-retinal ganglion cells (Rusoff and Dubin, 1978; Dann et al., 1987, 1988; Wong and Hughes, 1988). Size constancy would be maintained if a decrease in the relative convergence from photoreceptors/bipolars providing the functional drive to the RF center occurs. This model implies a dynamic sculpturing process of the functional synaptic drive to the $\beta$-retinal ganglion cells (Peichl and Wassle, 1983; Saito, 1983; Stanford, 1987; Sterling et al., 1988). As the size of the ganglion cell's dendritic arbor increases, the photoreceptor/bipolar inputs would reduce their divergence to neighboring $\beta$-ganglion cell dendritic arbors and, thus, the functional convergence onto these same cells.

Mechanisms that could account for the postnatal reduction in RF center sizes of cluster $1\left(X_{-}\right) L_{G N}$ neurons are illustrated in Figure 13, $C-F$. In the adult, the RF center radius of the cluster 1 (X-) retinal ganglion cells and $\mathrm{LGN}_{d}$ neurons at $>10^{\circ}$ eccentricity are statistically similar ( 82 vs $70 \mu \mathrm{m}, p>0.10$ ), suggesting that the dominant functional drive to a single $\mathrm{LGN}_{\mathrm{d}} \mathrm{X}$-cell in the adult may be provided by a single retinal ganglion cell (Mastronarde, 1987; Freeman et al., 1988). Therefore, the larger RF centers observed for peripheral cluster 1 (X-) $\operatorname{LGN}_{d}$ cells $4 \frac{11}{2}$ weeks after birth could result from functional convergence of a greater number of ganglion cells onto each $\mathrm{LGN}_{\mathrm{d}}$ neuron in the kitten (Fig. 13, C, D). In the 41/2-week-old kitten, input from several cluster $1(\mathrm{X}$-) retinal ganglion cells, with spatially offset RF centers, would produce a larger RF center for the recipient $\mathrm{LGN}_{d}$ neuron. In support of this mechanism, at 3-4 weeks postnatally the terminal arbors of $\mathrm{X}$-retinal axons are larger than those of adult X-retinal ganglion cells (Sur et al., 1984) and could produce the greater convergence ratios in the neonate illustrated in Figure $13, C, D$. Alternatively, the convergence ratio from retina to $\mathrm{LGN}_{\mathrm{d}}$ peripheral cluster 1 (X-) cells may remain unchanged during development, but the amount of overlap in the dendritic fields of neighboring ganglion cells providing the primary drive to the $\mathrm{LGN}_{\mathrm{d}}$ neuron may increase in the adult (Fig. 13, E, F). 


\section{References}

Albus, K., and W. Wolf (1984) Early postnatal development of neuronal function in kitten's visual cortex: A laminar analysis. J. Physiol. (Lond.) 348: 153-185.

Berardi, N., and M. C. Morrone (1984) Development of $\gamma$-aminobutyric acid mediated inhibition of X-cells of the cat lateral geniculate nucleus. J. Physiol. (Lond.) 357: 525-537.

Berkley, M. A. (1984) Contour-dependent visual after effects in the cat: Behavioral studies. Invest. Ophthalmol. Vis. Sci. (Suppl.) 25:314.

Blake, R., and W. Martens (1981) Critical bands in cat spatial vision. J. Physiol. (Lond.) 314: 175-187.

Bonds, A. B., and R. D. Freeman (1978) Development of optical quality in the kitten eye. Vision Res. 18: 391-398.

Braastad, B. O., and P. Heggelund (1985) Development of spatial receptive-field organization and orientation selectivity in kitten striate cortex. J. Neurophysiol. 53: 1158-1178.

Braddick, O., F. W. Campbell, and J. Atkinson (1978) Channels in vision: Basic aspects. In Handbook of Sensory Physiology, Vol. 7, R. Held, H. W. Leibowitz, and H.-L. Teuber, eds., pp. 3-38, Springer, Berlin.

Dann, J. F., E. H. Buhl, and L. Peichl (1987) Dendritic maturation in cat retinal ganglion cells: A Lucifer yellow study. Neurosci. Lett. 80: 21-26

Dann, J. F., E. H. Buhl, and L. Peichl (1988) Postnatal dendritic maturation of alpha and beta ganglion cells in cat retina. J. Neurosci. 8: 1485-1499.

Derrington, A. M. (1984) Development of spatial frequency selectivity in striate cortex of vision-deprived cats. Exp. Brain Res. 55: 431437

Derrington, A. M., and A. F. Fuchs (1979) Spatial and temporal properties of $\mathrm{X}$ and $\mathrm{Y}$ cells in the cat lateral geniculate nucleus. J. Physiol. (Lond.) 293: 347-364

Derrington, A. M., and A. F. Fuchs (1981) The development of spatialfrequency selectivity in kitten striate cortex. J. Physiol. (Lond.) 316 $1-10$.

Derrington, A. M., and P. Lennie (1982) The influence of temporal frequency and adaptation level on receptive field organization of retinal ganglion cells in cat. J. Physiol. (Lond.) 333: 343-366.

DeValois, R. L., and K. K. DeValois (1980) Spatial vision. Annu. Rev. Psychol. 31: 309-341.

Enroth-Cugell, C., and J. G. Robson (1966) The contrast sensitivity of retinal ganglion cells of the cat. J. Physiol. (Lond.) 187: 517-552.

Enroth-Cugell, C., J. G. Robson, D. E. Schweitzer-Tong, and A. B. Watson (1983) Spatio-temporal interactions in cat retinal ganglion cells showing linear spatial summation. J. Physiol. (Lond.) 341: 279307.

Freed, M. A., and P. Sterling (1988) The on-alpha ganglion cell of the cat retina and its presynaptic cell types. J. Neurosci. 8: 2303-2320.

Freeman, A. W., B. G. Cleland, and M. W. Levine (1988) The transfer of visual information through the thalamus. Neurosci. Lett. (Suppl.) 30: $\mathbf{S 6 7 .}$

Freeman, R. D., and C. E. Lai (1978) Development of the optical surfaces of the kitten eye. Vision Res. 18: 399-407.

Fregnac, Y., and M. Imbert (1984) Development of neuronal selectivity in primary visual cortex of cat. Physiol. Rev. 64: 325-434.

Friedlander, M. J. (1982) Structure of physiologically classified neurons in the kitten dorsal lateral geniculate nucleus. Nature 300:180183.

Friedlander, M. J. (1984) The postnatal development of the kitten dorsal lateral geniculate nucleus. In Development of Visual Pathways in Mammals, J. Stone, ed., pp. 155-173, Liss, New York.

Friedlander, M. J., and J. S. Tootle (1989) Postnatal anatomical and physiological development of the visual system. In Development of Sensory Systems in Mammals, J. R. Coleman, ed., Wiley, New York (in press).

Friedlander, M. J., K. A. C. Martin, and C. Vahle-Hinz (1985) The structure of the terminal arborizations of physiologically identified Y-retinal ganglion cell axons in the kitten. J. Physiol. (Lond.) 359 : 293-313.

Hamasaki, D. I., and J. T. Flynn (1977) Physiological properties of retinal ganglion cells of 3-week-old kittens. Vision Res. 17: 275-284.

Hamasaki, D. I., and V. G. Sutija (1979) Development of X- and Y-cells in kittens. Exp. Brain Res. 35: 9-23.
Hochstein, S., and R. M. Shapley (1976a) Quantitative analysis of retinal ganglion cell classification. J. Physiol. (Lond.) 262: 237-264.

Hochstein, S., and R. M. Shapley (1976b) Linear and nonlinear subunits in Y cat retinal ganglion cells. J. Physiol. (Lond.) 262: 265-284.

Ikeda, H., and K. E. Tremain (1978) The development of spatial resolving power of lateral geniculate neurons in kittens. Exp. Brain Res. 31: 193-206.

Kulikowski, J. J., S. Marcelja, and P. O. Bishop (1982) Theory of spatial position and spatial frequency relations in the receptive fields of simple cells in the visual cortex. Biol. Cybernet. 43: 187-198.

Lehmkuhle, S., K. E. Kratz, S. C. Mangel, and S. M. Sherman (1980) Spatial and temporal sensitivity of $\mathrm{X}$ - and $\mathrm{Y}$-cells in dorsal lateral geniculate nucleus of the cat. J. Neurophysiol. 43: 520-541.

Linsenmeier, R. A., L. J. Frishman, H. G. Jakiela, and C. Enroth-Cugell (1982) Receptive-field properties of X-and Y-cells in the cat retina derived from contrast sensitivity measurements. Vision Res. 22: 1173 1183.

Mangel, S. C., J. R. Wilson, and S. M. Sherman (1983) Development of neuronal response properties in the cat dorsal lateral geniculate nucleus during monocular deprivation. J. Neurophysiol. 50:240-264.

Mason, C. A. (1982) Development of terminal arbors of retinogeniculate axons in the kitten. II. Electron microscopical observations. Neuroscience $7: 561-587$

Mason, C. A. (1983) Postnatal maturation of neurons in the cat's lateral geniculate nucleus. J. Comp. Neurol. 217: 458-469.

Mastronarde, D. N. (1987) Two-classes of single-input X-cells in cat lateral geniculate nucleus. II. Retinal inputs and the generation of receptive-field properties. J. Neurophysiol. 57: 381-413.

Movshon, J. A., and R. C. Van Sluyters (1981) Visual neural development. Annu. Rev. Psychol. 32: 477-522.

Movshon, J. A., I. D. Thompson, and D. J. Tolhurst (1978) Spatial and temporal contrast sensitivity of neurons in areas 17 and 18 of the cat's visual cortex. J. Physiol. (Lond.) 283: 101-120.

Peichl, L., and H. Wassle (1981) Morphological identification of onand off-centre brisk transient ( $\mathrm{Y}$-) cells in the cat retina. Proc. $\mathrm{R}$. Soc. London [Biol.] 212: 139-156.

Peichl, I... and H. Wassle (1983) The structural correlate of the receptive field centre of $\mathrm{X}$ ganglion cells in the cat retina. J. Physiol. (Lond.) 341: 309-324.

Robson, J. G. (1975) Receptive fields: Spatial and intensive representations of the visual image. In Handbook of Perception, Vol. 5, E. C. Carterette and M. P. Friedman, eds., pp. 81-116, Academic, New York.

Rodieck, R. W. (1965) Quantitative analysis of cat retinal ganglion cell responses to visual stimuli. Vision Res. 5: 583-601.

Kusoff, A. C., and M. A. Dubin (1977) Development of receptivefield properties of retinal ganglion cells in kittens. J. Neurophysiol. 40: $1188-1198$

Rusoff, A. C., and M. A. Dubin (1978) Kitten ganglion cells: Dendritic field size at 3 weeks of age and correlation with receptive field size. Invest. Ophthalmol. Vis. Sci. 17: 819-821.

Saito, H.-A. (1983) Morphology of physiologically identified X-, Yand W-type ganglion cells of the cat. J. Comp. Neurol. 221: 279-288.

SAS Institute, Inc. (1985) SAS User's Guide: Statistics, SAS Institute, Inc., Cary, NC

Shapley, R., and P. Lennie (1985) Spatial frequency analysis in the visual system. Annu. Rev. Neurosci. 8: 547-583.

Sherman, S. M., and P. D. Spear (1982) Organization of visual pathways in normal and visually deprived cats. Physiol. Rev. 62: 738855 .

Shotwell, S. L., C. J. Shatz, and M. B. Luskin (1986) Development of glutamic acid decarboxylase immunoreactivity in the cat's lateral geniculate nucleus. J. Neurosci. 6: 1410-1423.

So, Y. T., and R. Shapley (1979) Spatial properties of X-and Y-cells in the lateral geniculate nucleus of the cat and conduction velocities of their inputs. Exp. Brain Res. 36: 533-550.

So, Y. T., and R. Shapley (1981) Spatial tuning of cells in and around lateral geniculate nucleus of the cat: $X$ and $Y$ relay cells and perigeniculate interneurons. J. Neurophysiol. 45: 107-120.

Stanford, L. R. (1987) X-cells in the cat retina: Relationship between the morphology and physiology of a class of retinal ganglion cells. J. Neurophysiol. 58: 940-964.

Sterling, P., M. A. Freed, and R. G. Smith (1988) Architecture of rod and cone circuits to the on-beta ganglion cell. J. Neurosci. 8:623642 . 
Stone, J. (1983) Parallel Processing in the Visual System: The Classification of Retinal Ganglion Cells and Its Impact on the Neurobiology of Vision. Plenum, New York.

Sur, M., R. E. Weller, and S. M. Sherman (1984) Development of Xand $Y$-cell retinogeniculate terminations in kittens. Nature 310:246249.

Thibos, L. N., and W. R. Levick (1983) Spatial frequency characteristics of brisk and sluggish ganglion cells of the cat's retina. Exp. Brain Res. 51: 16-22,

Thorn, F., M. Gollender, and P. Erickson (1976) The development of the kitten's visual optics. Vision Res. 16: 1145-1149.

Tolhurst, D. J., and I. D. Thompson (1981) On the variety of spatial frequency selectivities shown by neurons in area 17 of the cat. Proc. R. Soc. London [Biol.] 213: 183-199.

Tootle, J. S., and M. J. Friedlander (1985) Postnatal development of spatial contrast sensitivity of neurons in the kitten dorsal lateral geniculate nucleus. Soc. Neurosi. Abstr. 11: 805.

Tootle, J. S., and M. J. Friedlander (1986) Pustnatal development of receptive field surround inhibition in kitten dorsal lateral geniculate nucleus. J. Neurophysiol. 56: 523-541.

Tootle, J. S., and M. J. Friedlander (1987a) Receptive field properties of kitten retinal ganglion cells derived from spatial contrast sensitivity measurements. Invest. Ophthalmol. Vis. Sci. (Suppl.) 28: 404.

Tootle, J. S., and M. J. Friedlander (1987b) Cluster analysis of cat retinal ganglion cells during postnatal development. Soc. Neurosci. Abstr. 13:589.
Troy, J. B. (1983a) Spatial contrast sensitivities of X and $Y$ type neurons in the cat's dorsal lateral geniculate nucleus. J. Physiol. (Lond.) 344: 399-417.

Troy, J. B. (1983b) Spatio-temporal interactions in neurons of the cat's dorsal lateral geniculate nucleus. J. Physiol. (Lond.) 344: 419432.

Vakkur, G. J., P. O. Bishop, and W. Kozak (1963) Visual optics in the cat, including posterior nodal distance and retinal landmarks. Vision Res. 3: 289-314.

Westheimer, G. (1984) Spatial vision. Añnu. Rèv. Psychol. 35: 201226.

Wilson, J. R., D. E. Tessin, and S. M. Sherman (1982) Development of the electrophysiological properties of Y-cells in the kitten's medial interlaminar nucleus. J. Neurosci. 2: 562-571.

Winfield, D. A., and T. P. S. Powell (1980) An electron microscopical study of the postnatal development of the lateral geniculate nucleus in the normal kitten and after eyelid suture. Proc. R. Soc. London [Biol.] 210: 197-210.

Winfield, D. A., R. W. Hiorns, and T. P. S. Powell (1980) A quantitative electron-microscopical study of the postnatal development of the lateral geniculate nucleus in normal kittens and in kittens with eyelid suture. Proc. R. Soc. London [Biol.] 210: 211-234.

Wong, R. D. L., and A. Hughes (1988) Development of visual resolution in the cat retina. Neurosci. Lett. (Suppl.) 30: S141. 